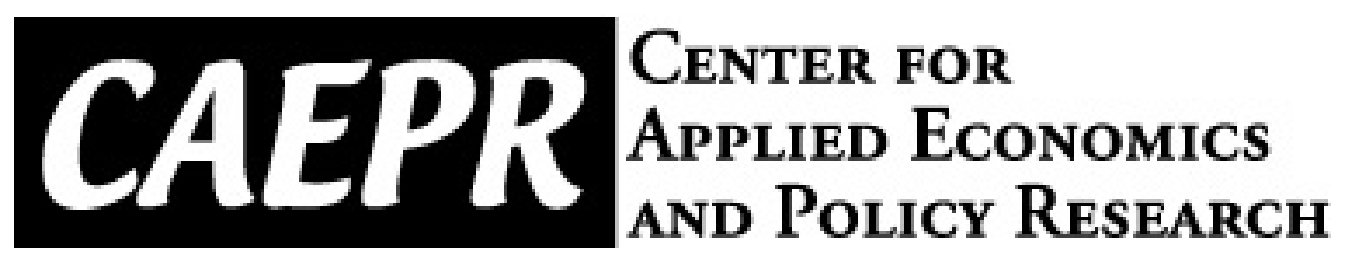

CAEPR Working Paper

\#009-2010

\title{
Inequality and Education Funding: Theory and Evidence from the U.S. School Districts
}

\section{Calin Arcalean and loana Schiopu ESADE Business School}

September, 2010

This paper can be downloaded without charge from the Social Science Research Network electronic library at: http://ssrn.com/abstract=1722167.

The Center for Applied Economics and Policy Research resides in the Department of Economics at Indiana University Bloomington. CAEPR can be found on the Internet at: http://www.indiana.edu/ caepr. CAEPR can be reached via email at caepr@indiana.edu or via phone at 812-855-4050.

(C)2010 by Calin Arcalean and loana Schiopu. All rights reserved. Short sections of text, not to exceed two paragraphs, may be quoted without explicit permission provided that full credit, including $($ ) notice, is given to the source. 


\title{
Inequality and Education Funding: Theory and Evidence from the U.S. School Districts*
}

\author{
Calin Arcalean \\ ESADE Business School
}

\author{
Ioana Schiopu ${ }^{\dagger}$ \\ ESADE Business School
}

September 2010

\begin{abstract}
We investigate the relationship between inequality and education funding in a model of probabilistic voting over public education spending where the private option is available. A change in inequality can have opposite effects at different income levels: higher inequality decreases public spending per student and increases enrollment in public schools in poor economies, while the opposite holds in the rich ones. A change in the tax base can also have non-monotonic effects. We also study the implications of different voting participation across income groups. The predictions of the model are supported by U.S. school district-level data.
\end{abstract}

JEL Codes: D72, H42, I21, I22.

Keywords: Education funding, Inequality, Political Economy.

*We thank Matthias Doepke, Gerhard Glomm, and Kim Huynh for useful comments and suggestions. We also thank seminar participants at Universitat Autònoma de Barcelona and Universidade de Vigo. The usual caveat applies. Financial support from Banc Sabadell is gratefully acknowledged.

${ }^{\dagger}$ Corresponding author. Email: ioana.schiopu@esade.edu, Department of Economics, ESADE, Ramon Llull University, Avenida de Torreblanca 59, 08172 Sant Cugat del Vallès, Barcelona, Spain, phone: +34 934952327. 


\section{Introduction}

This paper investigates the relationship between income inequality and the determination of education funding. The worldwide surge in income inequality in the last decades, the importance of human capital for individual and national prosperity as well as the rising pressures on public budgets make this a critical issue. However, the literature studying the effects of inequality on public education spending (and, more generally, on public goods provision and income redistribution) has yet to reach a consensus. For example, Lindert (1996) finds a negative relationship between inequality and public education spending in a sample of OECD countries. Using U.S. state level data, de la Croix and Doepke (2009) find that higher inequality is positively associated with public spending per student and negatively correlated with public spending per capita. Corcoran and Evans (2009) find that rising inequality within U.S. school districts is associated with higher local revenues per pupil.

Given these inconclusive results, in this paper we investigate the issue further. In the theoretical part, we provide a model that reconciles the findings of the previous literature, by showing that, in fact, the relationship of inequality and public school funding can be non-monotonic, i.e. negative at low levels of income and positive otherwise. We consider a political economy model of public education provision with a private schooling option and endogenous fertility decisions, similar to de la Croix and Doepke (2009). Building on this framework, we model household income heterogeneity to be consistent with the skewness of empirical income distributions, where the median is lower than the mean income.

If education is a normal good, the desired education quality increases with income. Tax financed uniform public education quality is insufficient for the rich parents who choose to send their children to a private school. Ceteris paribus, the higher the public school quality, the lower the private enrollment share. The availability of a private choice generates an endogenous income threshold that separates public and private school users. Moreover, in our model, fertility is connected to the school choice, with the private school users choosing a lower fertility rate than the households that opt for public schooling. For transparency, the fertility is constant within the two groups.

The equilibrium public spending arises as the politically mediated balance between the conflicting interests of these two groups. On the one hand, those opting for private schooling want to minimize the tax burden. On the other hand, those who choose public schooling, want to ensure adequate spending per student.

To see how the shape and the location of the income distribution affect this political balance, consider, for example, an exogenous mean preserving spread. First, this produces a shape effect: it decreases the size of the middle class, adding (asymmetrically) mass to the tails of the distribution. 
The initial position of the income threshold relative to the tails is critical in determining how the relative size of the two groups responds to an increase in inequality: if the threshold is initially located sufficiently far in the right tail, the share of private school users goes up with higher income dispersion. As mentioned above, the location of the income threshold is driven by the relative quality of public education. While this depends on the equilibrium tax rate and public school enrollment, it also depends on the tax base in the economy, which in our model is proportional to the average income.

Second, as equilibrium policies change, households adjust their education choices. Thus, the mean preserving spread leads to a shift in the critical income level, inducing an additional threshold effect. The direction and magnitude of this shift also depend on the relative quality of public education and hence on the average income. Together with the shape effect, the movement of the threshold in response to higher inequality determine the overall change in the political support for public spending.

We study how the interplay of these two effects determines the equilibrium education spending and enrollment in two counterfactual experiments: a) an increase in the tax base keeping income dispersion constant and b) a mean preserving spread of the income distribution. Our analysis yields two main findings.

First, generalizing results in the previous literature, we show that the relationship between inequality and public spending per student can be non-monotonic, depending on the average income level in the economy. A mean preserving spread decreases public spending per student but increases tax rates (spending per capita) and public school enrollments in low income economies, while it has opposite effects at high income levels. Furthermore, a marginal increase in the tax base, holding income dispersion constant, can also have non-monotonic effects.

Second, both the tax base and inequality effects on redistribution depend critically, not only on the level of the average income per capita, but also on the parental preferences for quality versus quantity of children. The non-monotonic relationships described above obtain only when the utility weight of the number of children is moderate. When the concern for the number of children is high, an increase in income dispersion lowers the public spending per student, despite higher taxation, while an increase in the tax base generates opposite effects. In contrast, when concern for the quantity of children is low, higher inequality decreases taxation but, as enrollment in public schools falls, spending per student increases.

As explained above, if the private option is available, the relative quality of public education determines the response of the economy to changes in the income distribution. Given some tax rate, the quality of public education depends on the average income (or the tax base) and the number of children enrolled in public schools, which is determined by parental preferences for fertility.

In order to get more intuition of the mechanisms in place, consider the case when 
fertility is low or the tax base is high. As the quality of public education is high, only the rich households use private schools. A mean preserving spread increases support for private education as some of the middle class is replaced with high income households, which prefer this option (the shape effect). This replacement also increases spending per student in public schools as resources are spread over fewer children. On the other hand, some middle income households are replaced by poorer families (again, the shape effect). However, since both household types choose public schooling and hence have identical fertility rates in our model, this replacement neither generates extra support for the public option nor does it decrease its quality. Therefore, marginal households strictly prefer public education, i.e. the indifference income threshold moves to the right of the income distribution (the threshold effect). Nonetheless, since the income threshold is relatively far in the right tail, its effect is dominated in magnitude by the shape effect. Thus, a mean preserving spread increases the support for private education and lowers taxes. While both public school enrollment and the tax rate decrease, more resources are available per student.

In contrast, when fertility rates are high or the tax base is low, public schools are of low quality, so both rich and some middle income households use private schools. A mean preserving spread increases support for public education as it replaces middle income households, that opt for private schools, with low income families, which prefer the free alternative (the shape effect). These families also choose high fertility rates, which further reduces (expected) spending per student. While this generates an endogenous shift of the marginal households into private schools (the threshold effect), the shape effect dominates in equilibrium, leading to higher enrollment in public schools and higher taxes, despite lower spending per student.

As a benchmark, we focus on probabilistic voting with households that have uniform political power. Asymmetric distribution of political power is typically associated with authoritarian regimes or partially democratic countries. However, it can also occur in well established democracies if, for example, voter turnout varies systematically with demographic characteristics. Indeed, the literature on political participation in the United States documents large turnout differences across income and age groups in national, state as well as local elections. While previous evidence applies to political participation in general, we show that education related votes are subject to similar disparities. Using data on school budget votes across school districts in the state of New York, we find a positive and significant correlation between socioeconomic indicators and involvement in local politics related to public education provision. Motivated by these findings, we then extend the model to include an income based index of political power and study its properties. $^{1}$

\footnotetext{
${ }^{1}$ Other papers that study asymmetrically distributed political power include Gans and Smart (1996), Bénabou (2000), de la Croix and Doepke (2009).
} 
In the empirical part, we test predictions arising from the theory using U.S. school district level data. We investigate the effects of the tax base and the income inequality on three schooling measures: the local public spending per student, the share of private enrollment and the local public spending per capita. The per capita spending can be interpreted as a measure of redistribution through education spending. We show that the aggregate relationship between spending and inequality reveals significant heterogeneities once the sample is split into quantiles of district average income. To deal with reverse causality, we use 1990 Census data to create a synthetic income distribution that captures residual inequality due to broader trends in economic activity that have shifted the aggregate income distribution and which individual school districts are too small to alter. We then use its mean and standard deviation to instrument the corresponding moments of the 2000 income distribution.

Both the least squares and the instrumental variables estimates lend strong support to predictions derived from the theoretical model with respect to enrollment and spending per student in public schools. Allowing for moderate asymmetries in the distribution of political power, in line with U.S. stylized facts, helps explain the behavior of per capita spending in both poor and rich school districts.

There is a large body of work studying the effects of inequality on public goods provision and income redistribution. However, as mentioned above, on both the theoretical and the empirical front, the literature has often reached inconsistent, even contradictory results. While some political economy papers argue that higher inequality leads to more redistribution through higher taxation (Meltzer and Richard (1981), Persson and Tabellini (1994), Bénabou (1997)), others find that more unequal or more heterogenous societies spend less on public goods (Soares (1998), de la Croix and Doepke (2009)). Glomm (2004) finds that the relationship between inequality and the amount of redistribution through public education services depends on the elasticity of substitution between consumption and the quality of education in the parent's utility. He finds that for empirically relevant value of this parameter, higher inequality generates less redistribution.

On the empirical side, a number of papers have found that support for redistribution and public goods provision is weaker in more unequal or more heterogenous societies (Goldin and Katz (1997), Alesina et al. (1999, 2001), Luttmer (2001)). Perotti (1996) finds no relationship between inequality and redistribution in democracies. Using data from the U.S. General Social Survey, Lind (2007) finds that inequality between different groups reduces redistribution, while within group inequality increases it. A more recent paper by Boustan et al. (2010) finds that rising inequality in cities and districts is associated with higher local revenue collection and expenditures.

Our paper contributes to the debate by providing more general theoretical results borne out in the data. Bénabou $(1997,2000)$ and Lee and Roemer (1998) focus on capital market imperfections to show that non-monotonic responses of redistribution to 
inequality are possible. Fernandez and Levy (2008) also find a non-monotonic effect of increased diversity in a model with income and preference heterogeneity. Complementary to these studies, we obtain a non-monotonic effect of inequality on redistribution at different levels of the average income per capita stemming from endogenous fertility and education choices. Also, in these papers, redistribution occurs through progressive taxation (Bénabou (2000)) or the provision of universal public education (Lee and Roemer (1998)). In the latter case, private and public investments in education are complements, but only the rich households top up.

In contrast, we focus on public education funding when a private alternative is available. In addition to modeling private schools, the framework presented here features endogenous fertility and education related tax deductions, reflecting important features in the organization of primary and secondary education in the United States. Another advantage of explicit opting out is that the endogenous threshold in education choices has a clear empirical counterpart as enrollments in public and private schools are easily observable. This facilitates testing the model's conclusions in more dimensions: spending per student, enrollments as well as per capita spending.

While our analysis builds on de la Croix and Doepke (2009), there are some important differences. On the one hand, a more flexible parametrization of the income distribution allow us to recover their results as a particular case. On the other hand, they use U.S. state level data to document correlations between inequality and education spending whereas we focus on school district data. Besides analyzing the effects of inequality on education provision, we shed light on the separate effects stemming from the tax base. As a distinct theoretical contribution, we parsimoniously embed in our framework a continuous measure of political power as a function of income, that preserves, under reasonable conditions, the uniqueness of the political equilibrium. Finally, we emphasize the interaction between parental preferences and the tax base in generating different responses of redistribution to inequality.

The remainder of the paper is structured as follows. Section 2 presents the model. Section 3 defines the equilibrium and derives the main analytical results. Section 4 documents significant participation differences in local politics related to public education provision and extends the benchmark model to analyze political power. Section 5 is devoted to the empirical evidence. Section 6 concludes. Proofs are relegated to Appendix A. Appendix B provides the data sources and summary statistics of the variables used in the empirical part. Appendix $\mathrm{C}$ details the construction of the instruments used in the estimations. Appendix D includes simulation results of the model's comparative statics. 


\section{The Model}

The economy is populated by a large number of households, which are heterogenous in income. The mass of households is normalized to one. Each household consists of an adult and a number of children. Children can get educated either in public schools, which are financed by tax revenues, or in private schools, financed by parental spending. This framework is similar to de la Croix and Doepke (2009). However, while they focus on a uniform distribution with mean one and standard deviation $\sigma$, here the household income is distributed according to a Pareto distribution, with p.d.f. $f$ and c.d.f. $F$, with parameters $y_{l}>0$ and $\alpha>2$, and support $y \in\left[y_{l} ; \infty\right) .^{2}$ The mean and standard deviation of the income distribution are given by:

$$
\mu=\frac{\alpha}{\alpha-1} y_{l} \text { and } \sigma=\frac{y_{l}}{\alpha-1} \sqrt{\frac{\alpha}{\alpha-2}} .
$$

Adults derive utility from household consumption $c$, the number of children $n$ and the quality of their education $E$, which can be private or public. Let $q$ denote the quality of public schools. Households can opt out of publicly provided education and send their children to a private school of quality $e^{r}$. The preferences are given by:

$$
u(c, n, E)=\ln (c)+\gamma[\ln (n)+\theta \ln (E)],
$$

where $E=q, e^{r}, \gamma>0$ and $\theta \in(0,1)$. Besides providing tractability, the assumption of logarithmic utility is consistent with the empirical evidence, which suggests that income and substitution elasticities of education spending have similar magnitudes (see Gradstein et al. (2005), pg. 50-51 for a discussion).

The government taxes the income from all households at the constant rate $\tau$. Tax revenues are used to finance public education of uniform quality for all children. For simplicity, we assume that quality of schooling is equal to the spending per student. The public policy is determined through a probabilistic voting mechanism described below.

\subsection{Household's problem}

The education expenditures are assumed to be tax deductible. As we will see further, this implies that the decisions regarding the quantity and quality of children are not affected by taxation. This assumption together with the endogenous fertility generates a constant tax base in equilibrium, which does not depend on the aggregate enrollment in public education. ${ }^{3}$ Together with the explicit possibility to opt out of public education,

\footnotetext{
${ }^{2}$ The p.d.f. is given by $f(y)=\alpha y_{l}^{\alpha} / y^{\alpha+1}$, for $y>y_{l}$ and zero otherwise. The c.d.f. is $F(y)=$ $1-\left(y_{l} / y\right)^{\alpha}$. The Pareto distribution is used for tractability reasons. Other distributions used in the literature, such as the log-normal, yield similar results.

${ }^{3}$ See also de la Croix and Doepke (2009).
} 
deductibility of education expenditures is in keeping with our focus on the U.S. case.

Rearing children involves a time cost. Denote by $\phi \in(0,1)$ the fraction of the parent's time spent raising a child. Given the quality of publicly provided education $q$ and the tax rate $\tau$, the household with income $y$ solves the following problem:

$$
\begin{gathered}
\max _{\{c \geq 0, n \geq 0, E \geq 0\}} u(c, n, E), \text { where } E=q, e^{r} \\
\text { s.t. }\left\{\begin{array}{cl}
c \leq(1-\tau) y(1-\phi n), & \text { if public education } \\
c \leq(1-\tau)\left[y(1-\phi n)-n e^{r}\right], & \text { if private education. }
\end{array}\right.
\end{gathered}
$$

Denote with $V^{p}$ and $V^{r}$ the utility of households whose children are educated in the public and private schools, respectively. A household with income $y$ that chooses public education solves the following problem:

$$
\max _{\{n \geq 0\}} V^{p}(y, n, q)=\ln [(1-\tau) y(1-\phi n)]+\gamma \ln (n)+\gamma \theta \ln (q),
$$

The solution of problem (4) is $n^{p}=\gamma /[\phi(1+\gamma)]$.

On the other hand, a household choosing private education solves:

$$
\max _{\{n \geq 0, e \geq 0\}} V^{r}(y, n, e)=\ln \{(1-\tau)[y(1-\phi n)-n e]\}+\gamma \ln (n)+\gamma \theta \ln \left(e^{r}\right) .
$$

The solutions to the problem (5) are $n^{r}=[\gamma(1-\theta)] /[\phi(1+\gamma)]$ and $e^{r}=\phi \theta y /(1-\theta)$. Comparing $n^{p}$ and $n^{r}$ we see that households that choose private schooling have a lower fertility than those sending the children to public schools.

Substituting $n^{p}$ in (4) and $n^{r}$ and $e^{r}$ in (5) we obtain the indirect utilities of households that choose public and private schooling, respectively:

$$
V^{p}(y, q)=\ln \left[\frac{(1-\tau) y}{1+\gamma}\right]+\gamma \ln \left[\frac{\gamma}{\phi(1+\gamma)}\right]+\gamma \theta \ln (q)
$$

and

$$
V^{r}(y, q)=\ln \left[\frac{(1-\tau) y}{1+\gamma}\right]+\gamma \ln \left[\frac{\gamma(1-\theta)}{\phi(1+\gamma)}\right]+\gamma \theta \ln \left[\frac{\phi \theta y}{1-\theta}\right] .
$$

A household will choose public education if and only if $V^{p}(y, q) \geq V^{r}(y, q)$. This inequality is satisfied for households with income lower than a threshold $\widetilde{y}$, given by:

$$
\widetilde{y}=\frac{q}{\phi \theta \delta}, \text { where } \delta=(1-\theta)^{\frac{1}{\theta}-1} \in(0,1) .
$$

Households choose the school type taking the other households' decisions as given. Denote by $\Psi$ the fraction of households that choose public schooling. In equilibrium, the individual choices must be consistent with the aggregate outcome, that is, the number of households with income lower than the threshold $\widetilde{y}$ should be equal to $\Psi$. The consistency 
condition is:

$$
\Psi(q)=F(\widetilde{y}(q))=\int_{y_{l}}^{\widetilde{y}(q)} f(y) d y=1-\left(\frac{y_{l}}{\widetilde{y}(q)}\right)^{\alpha} .
$$

Notice that $\Psi(q)$ is not equal to the fraction of children that go to public schools since the model incorporates fertility decisions. Thus, the fraction of children in public schools is given by:

$$
N(q)=\frac{n^{p} \Psi(q)}{n^{p} \Psi(q)+n^{r}(1-\Psi(q))} .
$$

Substituting the expressions for $n^{p}$ and $n^{r}$ we obtain:

$$
N(q)=\frac{\Psi(q)}{(1-\theta)+\theta \Psi(q)}>\Psi(q)
$$

\subsection{Government budget constraint}

The government budget is balanced:

$$
\int_{y_{l}}^{\widetilde{y}} q n^{p} f(y) d y=\tau \int_{y_{l}}^{\widetilde{y}}\left(1-\phi n^{p}\right) y f(y) d y+\tau \int_{\widetilde{y}}^{\infty}\left[\left(1-\phi n^{r}\right) y-n^{r} e^{r}\right] f(y) d y,
$$

where the left-hand side is the total public education spending, and the right-hand side the collected tax revenues from the two types of households (public and private school users, respectively). Using the expressions for $n^{p}, n^{r}$ and $e^{r}$ in the right-hand side of (12), we can see that the fraction of income that is taxable is constant across income groups and is equal to $y /(1+\gamma)$. As a result, the total tax base is constant and does not depend on the fraction of households choosing private schooling. Consequently, the right-hand side of the government budget constraint becomes $\tau \mu /(1+\gamma)$. Using the expression for $n^{p}$ in the left-hand side, we can express the quality of public schooling as a function of the fraction of households that choose public schools and the tax rate:

$$
q \Psi(q) \frac{\gamma}{\phi}=\tau \mu
$$

where $\mu=\int_{y_{l}}^{\infty} y f(y) d y$ is the average income and also the tax base.

\subsection{Voting on public education funding}

Fertility and education choices are made before voting takes place but in equilibrium, agents have perfect foresight regarding its outcome. This timing reflects sizeable differences in the relative costs and time horizons of the decisions involved. While public education spending is usually decided through yearly budget votes, fertility decisions 
cannot be easily adjusted at this frequency and depend largely on "pre-determined" characteristics, such as income, education level, race, religion, etc. A similar argument applies to the choice between public and private schooling, which in the U.S. is tightly connected to residential choice and therefore can entail substantial switching costs.

The public policies are determined through probabilistic voting. The voting problem is unidimensional, i.e. once the tax rate is chosen, the spending per student $q$ is determined from (13). Consider a set-up with two political parties, each proposing a program. Voters care about the education policy proposed but also about a second dimension of the electoral platform, called "ideology". The probability that an individual votes for a party thus depends on her ideological bias toward the party's proposed platform. The results of the elections are a random event, each party having a probability of winning.

The ideological preferences are assumed to be orthogonal to those on public policy. Thus, the probability that a person votes for a certain party (and the party vote share) is a smooth function of the distance between the two platforms. This framework has a unique equilibrium in which both parties converge to the same platform (see Persson and Tabellini (2002)), which maximizes the following social welfare function:

$$
W(\tau)=\int_{y_{l}}^{\widetilde{y}} u\left(y, n^{p}, q, \tau\right) p(y) f(y) d y+\int_{\widetilde{y}}^{\infty} u\left(y, n^{r}, e^{r}, \tau\right) p(y) f(y) d y
$$

subject to the government budget constraint (13).

The first and second terms of the welfare function are the aggregate utilities of the households that choose public and private education, respectively. The term $p(y)$ captures the political power of the group. We first assume $p(y)=1$, that is, all voters have the same political power. Later, we relax this assumption.

Note that the income threshold $\widetilde{y}$ is taken as given in the maximization, in keeping with the assumption of that fertility and education choices are predetermined when the vote takes place. While making the analysis more tractable, this assumption is still consistent, in equilibrium, with perfect foresight: the expected and the actual shares of households that choose public schooling are equal. ${ }^{4}$

Substituting the indirect utility functions, (6) and (7), in (14) and grouping terms, we get:

$$
\begin{gathered}
W(\tau)=\ln \left(\frac{1-\tau}{1+\gamma}\right)+\gamma \ln \left[\frac{\gamma}{\phi(1+\gamma)}\right]+\gamma \theta \ln (q(\tau)) \int_{y_{l}}^{\widetilde{y}} f(y) d y+ \\
\int_{\widetilde{y}}^{\infty}\left\{\gamma \ln (1-\theta)+\gamma \theta \ln \left[\frac{\phi \theta y}{1-\theta}\right]\right\} f(y) d y .
\end{gathered}
$$

Since only the first and the third term are functions of the policy variables, the welfare

\footnotetext{
${ }^{4}$ Nechyba (1999) takes a somewhat similar approach in a multi-community model where public education spending is decided by majority voting.
} 
can be rewritten as

$$
W(\tau)=\ln (1-\tau)+\gamma \theta \Psi \ln (q(\tau))
$$

where $\Psi(\widetilde{y})$ is taken as given. Substituting $q$ from (13) and taking the first order condition with respect to $\tau$ yields:

$$
\tau=\frac{\gamma \theta \Psi}{1+\gamma \theta \Psi}
$$

Everything else equal, the tax increases with the households' concern for children as well as with the enrollment. In the next section we define the equilibrium and study its properties.

\section{$3 \quad$ Equilibrium analysis}

Definition 1. A politico-economic equilibrium is an income threshold $\widetilde{y}$, an allocation $\left(c^{p}, n^{p}\right)$ if $y \leq \widetilde{y},\left(c^{r}, n^{r}, e^{r}\right)$ if $y>\widetilde{y}$, and a public policy $(q, \tau)$ such that:

(i) household's decisions solve problems (4) or (5), given public policy $(q, \tau)$;

(ii) the government budget is balanced, i.e. it satisfies (13);

(iii) the tax rate $\tau$ solves the social welfare maximization problem (14);

(iv) the consistency condition (9) is satisfied.

Next, we solve for the equilibrium threshold $\widetilde{y}$. To minimize clutter, we drop functional dependencies where possible. We use the expression of $q,(13)$, and $\tau,(16)$ in (8) to obtain:

$$
\widetilde{y}=\frac{\mu}{\delta} \frac{1}{1+\gamma \theta \Psi(\widetilde{y})}
$$

Using the consistency condition, (9) yields the following expression in $\widetilde{y}$ :

$$
\widetilde{y}=\frac{\mu}{\delta} \frac{1}{1+\gamma \theta\left[1-\left(\frac{y_{l}}{\widetilde{y}}\right)^{\alpha}\right]} .
$$

Proposition 1. There exist a unique and interior equilibrium income threshold $\widetilde{y}^{*} \in$ $\left(y_{l}, \infty\right)$ that solves equation (18) (proof in the Appendix).

Note that the equilibrium threshold $\widetilde{y}^{*}$ is always interior because the support of the income distribution does not have an upper bound. However, when $\widetilde{y}^{*} \rightarrow \infty$, the fraction of students in public schools goes asymptotically to 1 .

Proposition 1 implies there is a unique equilibrium public spending per student:

$$
q^{*}=\widetilde{y}^{*} \phi \theta \delta=\frac{\phi \theta \mu}{1+\gamma \theta\left[1-\left(\frac{y_{l}}{\widetilde{y}^{*}}\right)^{\alpha}\right]} .
$$


We use equations (9) and (19) to express $\Psi^{*}$ as a function of $q^{*}$ :

$$
\Psi^{*}=\frac{1}{\gamma \theta}\left(\frac{\phi \theta \mu}{q^{*}}-1\right)
$$

Using (9) in (11), we obtain the equilibrium enrollment in public schools:

$$
N^{*}=\frac{\Psi^{*}}{(1-\theta)+\theta \Psi^{*}}, \text { where } \Psi^{*}=1-\left(\frac{y_{l}}{\widetilde{y}^{*}}\right)^{\alpha} .
$$

In the following, we investigate how changes in the income distribution of a school district affect the main policy variables. We focus on two experiments: a) a change in the average income per capita, $\mu$, keeping the standard deviation, $\sigma$, constant and b) a mean preserving spread in the income distribution.

\subsection{A change in the mean income (tax base)}

Now we analyze the effects of changing the mean income, $\mu$, on the equilibrium public spending per student $q$, the tax rate $\tau$, and enrollment in public schools $N$. Recall that in our model $\mu$ also represents the tax base.

Denote by $f(\mu, \sigma)=\left[y_{l}(\mu, \sigma) / \widetilde{y}(\mu, \sigma)\right]^{\alpha(\mu, \sigma)}$. The derivative of $N^{*}$ with respect to $\mu$ is:

$$
\begin{aligned}
\frac{\partial N^{*}}{\partial \mu} & =\frac{1-\theta}{\left[(1-\theta)+\theta \Psi^{*}\right]^{2}} \frac{\partial \Psi^{*}}{\partial \mu} \\
& =\frac{1-\theta}{\left[(1-\theta)+\theta \Psi^{*}\right]^{2}} \frac{\phi}{\gamma} \frac{q^{*}-\mu \frac{\partial q^{*}}{\partial \mu}}{\left(q^{*}\right)^{2}},
\end{aligned}
$$

where

$$
\frac{\partial q^{*}}{\partial \mu}=\frac{\phi \theta\left\{1+\gamma \theta(1-f)+\mu \gamma \theta \frac{\partial f(\mu, \sigma)}{\partial \mu}\right\}}{[1+\gamma \theta(1-f)]^{2}} .
$$

Using (16) and (20) we obtain the change in the equilibrium tax rate with respect to $\mu$ :

$$
\frac{\partial \tau^{*}}{\partial \mu}=\frac{\gamma \theta(1-\theta)}{\left(1+\gamma \theta \Psi^{*}\right)^{2}} \frac{1}{\left(1-\theta N^{*}\right)^{2}} \frac{\partial N^{*}}{\partial \mu} .
$$

Studying the properties of the function $\partial N^{*} / \partial \mu$ yields the following results.

Proposition 2. Let $\underline{\gamma}=[(2 /(\delta e))-1] /\left\{\theta\left[1-e^{-2}\right]\right\}$ and $\bar{\gamma}=[(1 / \delta)-1] /\{\theta[1-(1 / e)]\}$, where $e$ is the Euler constant.

1) If $\gamma \leqslant \underline{\gamma}$, then $\partial N^{*} / \partial \mu>0$ and $\partial \tau^{*} / \partial \mu>0$;

2) If $\gamma \geqslant \bar{\gamma}$, then $\partial N^{*} / \partial \mu<0$ and $\partial \tau^{*} / \partial \mu<0$;

3) If $\gamma \in(\underline{\gamma}, \bar{\gamma})$, then there exist a unique $\widehat{\mu} \in(0, \infty)$ such that

3.1) if $\mu \in(0, \widehat{\mu}]$, then $\partial N^{*} / \partial \mu \leqslant 0$ and $\partial \tau^{*} / \partial \mu \leqslant 0$; 
3.2) if $\mu \in(\widehat{\mu}, \infty)$, then $\partial N^{*} / \partial \mu>0$ and $\partial \tau^{*} / \partial \mu>0$;

(Proof in the Appendix).

The next proposition establishes sufficient conditions under which the equilibrium spending per student $q^{*}$ varies positively with the mean income.

Corollary 1. 1) If $\gamma \geqslant \bar{\gamma}$, then $\partial q^{*} / \partial \mu>0$;

2) If $\gamma \in(\underline{\gamma}, \bar{\gamma})$ there exists $\widetilde{\mu}>\widehat{\mu}$ such that $\partial q^{*} / \partial \mu>0$ on the interval $\mu \in(0, \widetilde{\mu})$ (Proof in the Appendix).

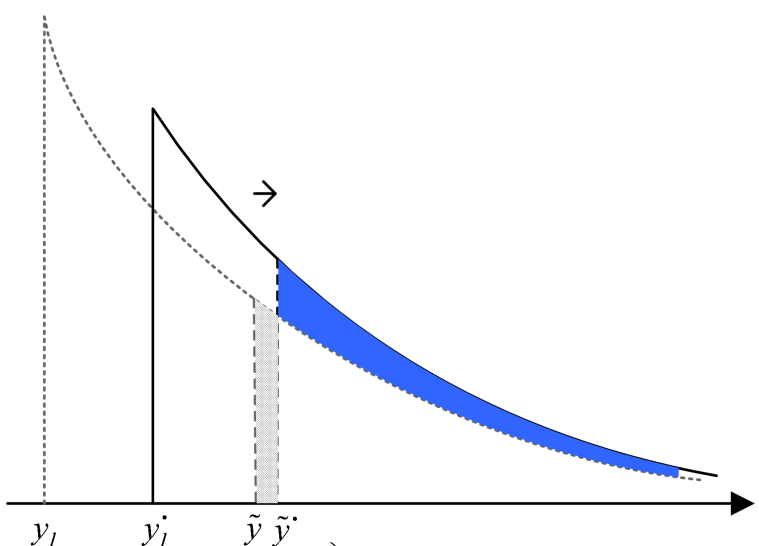

a)

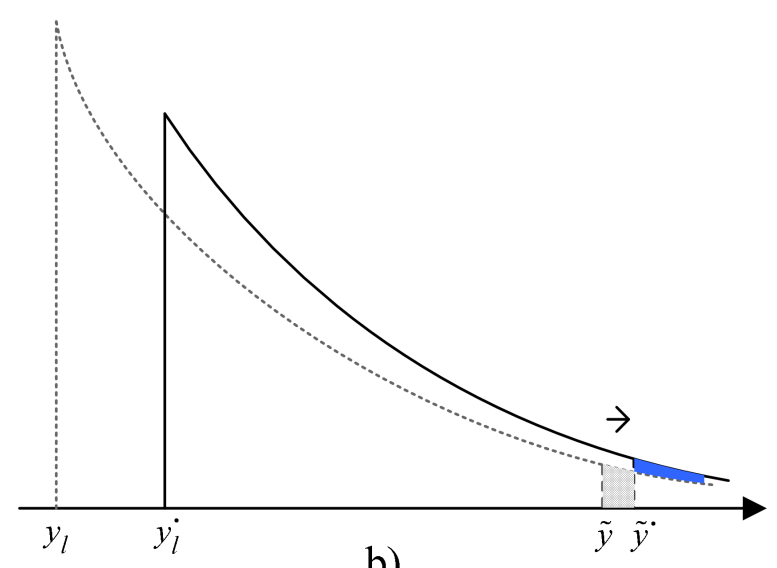

b)

Figure 1: An increase in the tax base (mean income per capita), indicated by dot variables (e.g. $\mu^{\bullet}>\mu$ ) and solid lines. Panel a: high fertility preference $(\gamma)$ or low tax base $(\mu)$. Panel b: low fertility preference or high tax base. The arrow indicates the endogenous change in the indifference threshold. Dark (light) shaded areas represent increases (decreases) in the support for private education.

As it is apparent from Proposition 2, the effects of an increase in the tax base depend on $\gamma$. Equilibrium fertility allocations $n^{p}$ and $n^{r}$ are increasing functions of $\gamma$, while private education spending $e^{r}$ does not depend on $\gamma .{ }^{5}$ We therefore interpret $\gamma$ as a relative weight of fertility in the parental preferences.

Everything else equal, a marginal increase in the tax base keeping dispersion constant has two effects. First, it adds relatively more rich and middle income households, so that, as $y_{l}$ increases, the right tail becomes thicker. The increase in the mass of relatively richer households has a positive effect on the demand for private education. Call this (exogenous) shape effect. Second, it increases the resources available for public education. This makes the households that were previously indifferent between private and public education to always choose the latter. Call this (endogenous) threshold effect. The two movements have opposing effects on the tax rate and equilibrium enrollment. Which

\footnotetext{
${ }^{5}$ As $\gamma$ increases, parents prefer fertility $(\gamma)$ over quality $(\gamma \theta)$ since since $\theta<1$.
} 
effect dominates depends on the quality of public education, defined as spending per student, relative to the private option.

Public education quality is low when few resources are available (low $\mu$ ) or when there are many children enrolled (high $\gamma$, i.e. high fertility), corresponding to case 2 and 3.1 in Proposition 2 . Panel a in figure 1 depicts this case. This implies a relatively large mass of rich households in the right tail choosing, in equilibrium, private education. An increase in $\mu$ further increases this mass, generating a large increase in the support for private education (the shape effect). It dominates the higher enrollment in public education by some middle income families caused by the threshold effect. Therefore the equilibrium tax and public enrollment decrease. However, the equilibrium spending per student can increase as the withdrawal of rich households from public education frees some resources.

Panel $b$ in figure 1 shows the case when the tax base $(\mu)$ is high or fertility preference $(\gamma)$ is low (regimes 1 and 3.2 in Proposition 2). In this case, the public education resources are high, so only the very rich households prefer private education. Thus, when the tax base increases, the shape effect generates a more modest boost of demand for private education than in the case above. Again, the threshold effect implies borderline households choose public education when average income increases marginally. However, the threshold effect dominates the shape effect in this case. Increased support for public education generates higher enrollment and taxes. Nonetheless, equilibrium spending per student can decrease if the increase in enrollment outpaces that in revenues.

\subsection{A mean preserving spread}

Next, we analyze the relationship between public policies and inequality - proxied by $\sigma$, the standard deviation of the income distribution. We perform a mean-preserving spread and study its implications on public spending per student, $q$, the tax rate, $\tau$, and the enrollment in public schools, $N$. Taking the derivative of $q^{*}$ with respect to $\sigma$ keeping $\mu$ constant yields:

$$
\begin{aligned}
\frac{\partial q^{*}}{\partial \sigma} & =\frac{\phi \theta \mu}{\{1+\gamma \theta[1-f(\mu, \sigma)]\}^{2}} \frac{\partial f(\mu, \sigma)}{\partial \sigma} \\
\frac{\partial N^{*}}{\partial \sigma} & =-\frac{1-\theta}{\left[(1-\theta)+\theta \Psi^{*}\right]^{2}} \frac{\partial f(\mu, \sigma)}{\partial \sigma} \\
\frac{\partial \tau^{*}}{\partial \sigma} & =-\frac{\gamma \theta}{\left(1+\gamma \theta \Psi^{*}\right)^{2}} \frac{\partial f(\mu, \sigma)}{\partial \sigma} .
\end{aligned}
$$

From the expressions above we see that spending per student varies inversely with public enrollment and the tax rate. Next, we study the properties of functions $\partial q^{*} / \partial \sigma$, $\partial N^{*} / \partial \sigma$, and $\partial \tau^{*} / \partial \sigma$. The results are summarized in the following proposition:

Proposition 3. Let $\underline{\gamma}=[(2 /(\delta e))-1] /\left\{\theta\left[1-e^{-2}\right]\right\}$ and $\bar{\gamma}=[(1 / \delta)-1] /\{\theta[1-(1 / e)]\}$, 
where $e$ is the Euler constant.

1) If $\gamma \leqslant \underline{\gamma}$, then $\partial \tau^{*} / \partial \sigma<0, \partial N^{*} / \partial \sigma<0, \partial q^{*} / \partial \sigma>0$

2) If $\gamma \geqslant \bar{\gamma}$, then $\partial \tau^{*} / \partial \sigma>0, \partial N^{*} / \partial \sigma>0, \partial q^{*} / \partial \sigma<0$;

3) If $\gamma \in(\underline{\gamma}, \bar{\gamma})$, then there exist a unique $\widehat{\mu} \in(0, \infty)$ such that

3.1) if $\mu \in(0, \widehat{\mu}]$, then $\partial \tau^{*} / \partial \sigma \geqslant 0, \partial N^{*} / \partial \sigma \geqslant 0$, $\partial q^{*} / \partial \sigma \leqslant 0$;

3.2) if $\mu \in(\widehat{\mu}, \infty)$, then $\partial \tau^{*} / \partial \sigma<0, \partial N^{*} / \partial \sigma<0$, $\partial q^{*} / \partial \sigma>0$;

(Proof in the Appendix).

The intuition of these results is the following. A mean preserving spread decreases the size of the middle class, adding mass to the tails of the income distribution (poor and rich households). This is the shape effect. Whether support for public education increases or not following this change in the shape of the distribution depends on the initial location of the indifference threshold. Thus, the endogenous response of this threshold to higher inequality generates an additional effect.

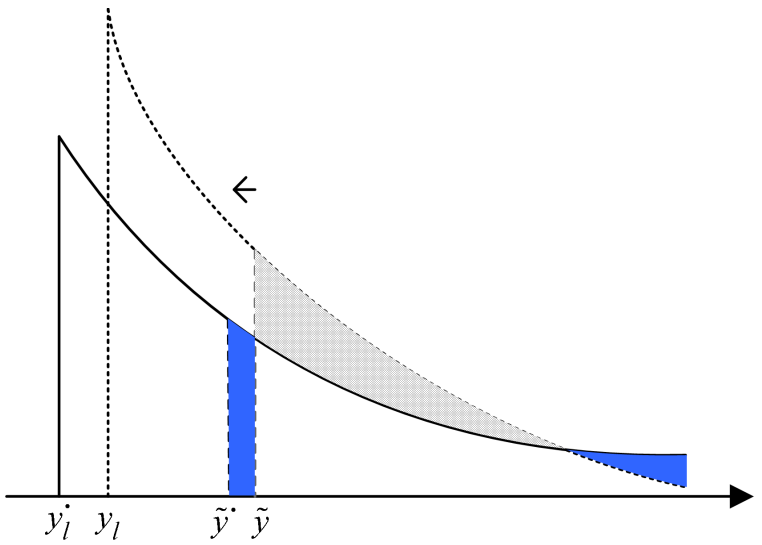

a)

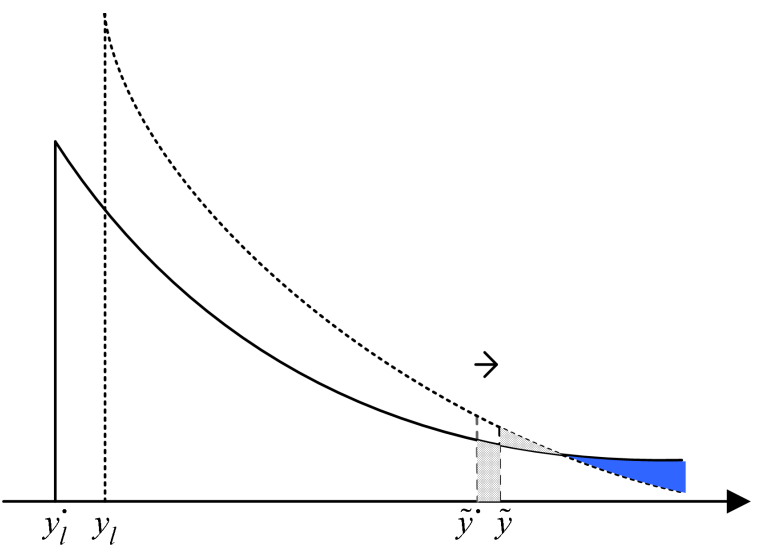

b)

Figure 2: A mean preserving spread, indicated by dot variables (e.g. $\sigma^{\bullet}>\sigma$ ) and solid lines. Panel a: high fertility preference $(\gamma)$ or low tax base $(\mu)$. Panel b: low fertility preference or high tax base. The arrow indicates the endogenous change in the indifference threshold. Dark (light) shaded areas represent increases (decreases) in the support for private education.

Again, consider the case of low public education quality (low $\mu$ or high $\gamma$ ), corresponding to cases 2 and 3.1 in Proposition 3, and shown in panel a of figure 2. This implies that many rich and middle income households choose the private option. Thus, the indifference threshold lies relatively far from the right tail, in some middle income range. First, there are two opposing shape effects that arise under a mean preserving spread. On the one hand, the middle class shrinks and so does the support for private education. On the other hand, the mean preserving spread increases the mass of rich households in the right tail who send their children to private education. The overall effect on demand for public education thus depends on the relative magnitude of these opposing effects. 
Second, when public education is of low quality, an increase in inequality prompts the threshold households to switch to private education, as the mean preserving spread adds more poor, high fertility households in the left tail, which further reduce spending per student. This is the threshold effect. In this case, the negative effect on the demand for private education caused by the reduction of middle class dominates the positive effects stemming from the extra mass of rich households as well as the endogenous shift in the income threshold towards private schooling. As a result, the enrollment in public schools goes up and so does the tax rate. Despite the increase in revenues (and the extra resources made available by households who left public schools), spending per student is lower in equilibrium as middle income households (choosing lower fertility and private schooling) have been replaced by low income and high fertility households that benefit from public education.

Conversely, when the tax base $(\mu)$ is large or fertility preference $(\gamma)$ is low, such as in cases 1 and 3.2 in Proposition 3 (panel $b$ of figure 2), the resources for public schooling are higher and, compared with the case above, the mass of middle income households that prefer private education is lower. Thus, the negative effect on the demand for private education generated by a reduction of middle income class is weaker and it is likely to be dominated by the positive effect generated by an increase in the mass of rich households (the shape effects). Second, there is again a threshold effect. In this case, the marginal households strictly prefer public education when inequality increases. Since the indifference threshold is far in the tail, the increase in demand for private education from the extra mass of rich households dominates, generating a decrease in public enrollment and the tax rate. In equilibrium, tax revenues increase faster than public school enrollment, resulting in an increase in public spending per student.

To sum up, when inequality increases, the size of the poor and rich class increases at the expense of middle class. When the tax base is low enough, poor households steer the political process in their favor, raising the tax rate. As the tax base is constant, this increases the public spending per capita, or the size of redistribution. When the tax base is high, the interests of the rich households dominate. Thus, the tax rate and the size of redistribution go down. Interestingly, the per student spending in public education, being driven by the endogenous response of enrollment, decreases in the first case and increases in the second.

\section{Political power}

So far we have assumed each parent carries the same weight in the political process. Next, relying on previous literature as well as new empirical evidence specific to public education politics, we document that even in a well-established democracy, like the United States, political participation indicators, such as voter registration and turnout, 
are positively correlated with income across age and education levels. We then investigate the effects of this bias on public education provision within the theoretical framework.

\subsection{Political participation patterns across income groups}

Political participation patterns across income groups in the United States have been well documented in the literature (Verba et al. (1995), Rosenstone and Hansen (1993)). At national level, there are striking differences. The 2000 Voter Supplement of the Current Population Survey (CPS) reveals that among those in the 25-44 age group, less than $30 \%$ of those in the last income category (under $\$ 5000$ ) voted in the 2000 presidential elections while in the highest bracket $(\$ 75,000$ and over) the turnout was of $70 \%$. The propensity to vote is increasing in income across all age groups. However, it is much lower in the 18-24 age group, not exceeding $40 \%$ in the richest income bracket. Those of age 64 and over vote in proportions ranging from around $50 \%$ to almost $90 \%$ between in the lowest and the highest income groups. Similar patterns are revealed in the 2006 Congressional elections: $50.7 \%$ in the lowest income group (less than $\$ 10,000$ ) registered but only $24.3 \%$ voted, compared to $82.1 \%$ registration and $64.6 \%$ turnout in the highest bracket $(\$ 150,000$ and over).

However, in the case of the United States, despite an increasing weight of the federal outlays, public education funding is still decided largely at state and local level. One may assume that voters understand better, and thus are more concerned with local policies, which they can more easily tweak in their favor. Perhaps surprisingly, a few studies (Morlan (1984); Hajnal and Lewis (2003)) find the contrary: turnout in local elections is on average half that of national elections, with some cities performing much worse. These low figures suggest that disadvantaged segments of the population might be even less represented at local level. While little data is available at this level, in a recent study of mayoral and city council elections in Californian cities, Hajnal and Lewis (2003) find that an index of socioeconomic status - summarizing income, education, poverty and home ownership measures - is indeed a positive and highly significant correlate of voter turnout.

In the following, we use participation rates in school budget votes across school districts in the state of New York to document differences in political participation at school district level. The New York State Education Department provides vote counts from 2003-2004 budget votes. In order to obtain a measure of the turnout, we divide the number of voters to the number of adult persons in each school district. Comprehensive demographic data at district level is only available from the 2000 Census. However, these characteristics move slowly over time. ${ }^{6}$ We therefore use the Census numbers to compute

\footnotetext{
${ }^{6}$ Adult population counts for a representative sample of NY school districts from the 2005 American Community Survey show a correlation of 0.99 with the 2000 figures.
} 
voter turnout indicators. Across the 628 school districts in NY, the mean turnout is $14 \%$, with a maximum of $46 \%$ and a minimum of $3 \%$. Table 1 shows least squares regressions of the turnout variable on school district characteristics. Results confirm that participation in local public education politics is associated positively with household income, the share of population with college degrees and the share of population of age 65 or superior and negatively to the share of population living in poverty and the share of non-white population. While these correlations describe school district aggregates, taken together with the previous evidence on the determinants of political participation, they suggest that income and education differences generate asymmetric propensities to vote even in local political processes, like those related to the provision of public education.

Table 1: Voter turnout (\%) in 2003-2004 school budget votes in the state of New York

\begin{tabular}{lllll}
\hline \hline & $(1)$ & $(2)$ & $(3)$ & $(4)$ \\
\hline $\log ($ mean income $)$ & $3.10^{* * *}$ & 1.31 & -1.59 & $2.70^{* *}$ \\
& $(4.66)$ & $(1.05)$ & $(-1.24)$ & $(2.04)$ \\
Share 65+ & & $0.13^{* *}$ & $0.12^{* *}$ & 0.06 \\
& & $(2.17)$ & $(2.12)$ & $(1.10)$ \\
Share college & & $6.41^{*}$ & 4.68 & -0.79 \\
& & $(1.81)$ & $(1.44)$ & $(-0.26)$ \\
Share poverty & & & $-36.80^{* * *}$ & $-20.25^{* * *}$ \\
& & & $(-6.15)$ & $(-3.33)$ \\
Share non-white & & & & $-18.23^{* * *}$ \\
& & & & $(-8.39)$ \\
\hline Adj. R-Squared & 0.035 & 0.048 & 0.094 & 0.171 \\
$\mathrm{~N}$ & 628 & 628 & 628 & 628 \\
\hline \hline
\end{tabular}

Notes: The dependent variable is the voter turnout, measured as percentage, in 2003-2004 school budget votes in the state of New York. Mean district income is expressed in dollars. Share variables, such as the age, education and race controls are expressed in percentages. Robust standard errors within parantheses. ${ }^{*}$ indicates significance at the 10 percent level, ** indicates significance at the 5 percent level, ${ }^{* * *}$ indicates significance at the 1 percent level.

\subsection{Political power and public education provision}

We use the benchmark model to implement and study a general, yet parsimonious political power function that assigns more clout to the rich. Next, we show that under fairly general conditions the equilibrium continues to be unique. Finally, we analyze the effects of uneven political representation on the public education budget, enrollment and spending per student.

To model the direct dependence between income and political power, we define

$$
p(y)=y^{\nu}
$$


where $y$ is the income level and $\nu>0$. The welfare function (14) becomes

$$
\begin{gathered}
W(\tau)=\int_{y_{l}}^{\widetilde{y}}\left\{\ln \left[\frac{(1-\tau) y}{1+\gamma}\right]+\gamma \ln \left[\frac{\gamma}{\phi(1+\gamma)}\right]+\gamma \theta \ln (q)\right\} p(y) f(y) d y+ \\
\int_{\widetilde{y}}^{\infty}\left\{\gamma \ln (1-\theta)+\gamma \theta \ln \left[\frac{\phi \theta y}{1-\theta}\right]\right\} p(y) f(y) d y
\end{gathered}
$$

Then, using (27) and retaining the relevant terms simplifies the expression to

$$
W(\tau)=\ln (1-\tau)+\gamma \theta \Psi^{p} \ln (q)
$$

where $\Psi^{p}=1-\left(y_{l} / y\right)^{\alpha-\nu}$.

Notice that the only difference relative to (15), the aggregate welfare in the benchmark model, is the weight assigned to public education spending, which here is $\Psi^{p}$ rather than $\Psi=1-\left(y_{l} / y\right)^{\alpha}$. It is easy to see that $\Psi^{p}<\Psi$. Thus, when political power is directly proportional to income, the interests of the rich (lower taxes) have a higher weight in the aggregate welfare. Since they are using mostly private education, the social welfare function reflects the new political power balance by assigning a lower weight to public education provision.

The definition of equilibrium is similar to that in the benchmark model. The optimal tax rate is

$$
\tau^{p}=\frac{\gamma \theta \Psi^{p}}{1+\gamma \theta \Psi^{p}}
$$

while the private education income threshold is given by

$$
\widetilde{y}=\frac{\mu}{\delta} \frac{1}{\Psi} \frac{\Psi^{p}}{1+\gamma \theta \Psi^{p}} .
$$

Proposition 4. Let $\underline{\gamma}^{p}=(\exp (-\ln (1 / 2)-\ln \delta)-1) / \theta$. If $\gamma>\underline{\gamma}^{p}$, there exist a unique equilibrium income threshold $\widetilde{y}^{*} \in\left(y_{l}, \infty\right)$ that solves equation (29), $\forall \nu>0$. Moreover, uniqueness is ensured $\forall \gamma>0$, for sufficiently small $\nu$. (Proof in the Appendix)

In the benchmark model, higher public education enrollment translates into higher tax revenues as the tax rate increases with the propensity for public education and the tax base stays constant. However, now the optimal tax rate reflects the taste of rich households for private education. In the following we study how the main results in the previous section change when we allow for political power.

We numerically replicate the exercises in Propositions 2 and 3 with and without political power. We use $\phi=0.075, \theta=0.5$ and $\gamma=6$ in the benchmark model, corresponding to the case of intermediate fertility rates (case 3$).^{7}$

Figure 3 graphs the three policy variables - public school enrollment, public spending per capita and the tax rate - as functions of the average income per capita, keeping

\footnotetext{
${ }^{7}$ Simulation results assuming extreme preferences (case 1 and 2) are included in Appendix D.
} 
dispersion constant. The thin lines represent the benchmark model and the thick lines the model with political power.

Figure 3: Tax base effects
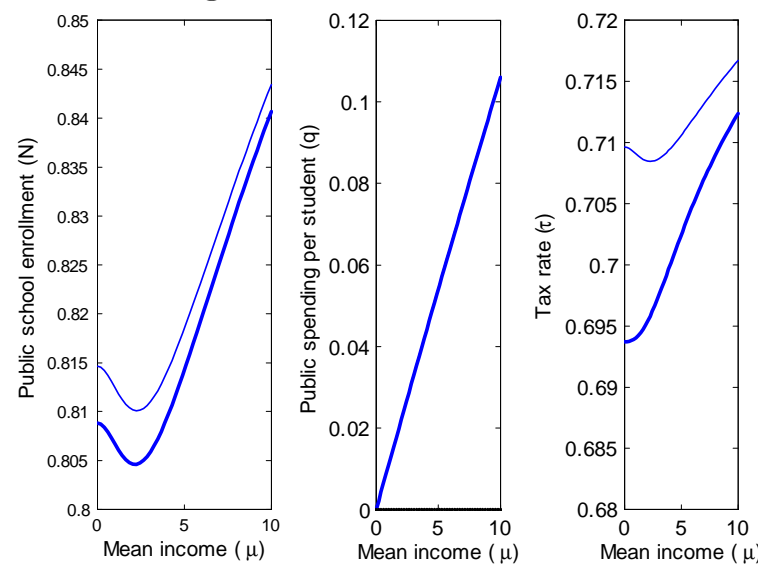

Main education variables as a function of the mean income (tax base), keeping dispersion constant, under political power $(\nu=0.3$, thick line) versus benchmark $(\nu=0$, thin line).

As expected, adding income correlated political weights lowers the tax rates at all income levels. However, lower taxation determines some households to switch to private education and thus enrollment in public schools also declines. Thus, public spending per student declines much less than revenues. Besides these level effects, political power induces tax rates to strictly increase with the mean income. In the benchmark model the tax rates follow a U-shaped pattern as a function of mean income for intermediate values of $\gamma$.

The thin lines in figure 4 display, from left to right, changes in the main variables, for a range of mean incomes when the standard deviation of the distribution increases by $10 \%$. Thus, in the leftmost panel, public school enrollment increases with inequality in poor districts but declines in more unequal rich districts, as already shown in Proposition 3. Then, we allow for political power by setting $\nu=0.3$. The thick lines depict similar changes with inequality. Rich households now have more power in setting the tax rate, such that higher inequality leads to lower tax rates in all districts as well as more abrupt declines in spending per student in poor districts. Case 3 in Proposition 3 shows that for intermediate values of the altruism coefficient $\gamma$, the equilibrium tax rate increases with inequality in poor districts, where the welfare of the relatively more numerous disadvantaged households depends on the quality of public schooling. This effect is overturned by allowing richer households to enjoy political power.

We have shown that augmenting the model to include political power preserves the uniqueness of the politico-economic equilibrium under fairly general conditions and induces tax rate and public spending per student to decrease more strongly with inequality. Moreover, the tax rate responds in a monotonic fashion to changes in inequality. 
Figure 4: Effects of a mean preserving spread
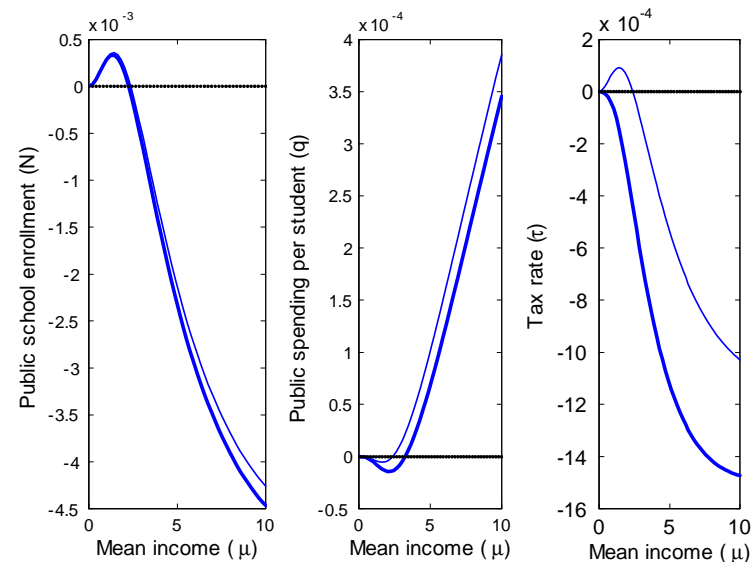

Changes in the main education variables from a 10 percent increase in income dispersion, for a given mean income, under political power $(\nu=0.3$, thick line) versus benchmark $(\nu=0$, thin line).

\section{Empirical evidence}

In this section we use U.S. school district level data to investigate the relationship between household income inequality and three schooling measures: the local public spending per student, the share of public enrollment and the local public spending per capita ( $q, N$ and $\tau$, respectively, in the model). Our analysis draws on school district (SD) demographic and financial data in 2000 from the National Center for Education Statistics (NCES) of the U.S. Department of Education. Details on the data sources and summary statistics are provided in Appendix B.

The empirical exercise is guided by the theoretical results in Section 3, where we separated the effects of the mean income and inequality on education provision. One important message of the analysis is that an increase in inequality can have opposing effects in poor and rich districts. More unequal poor districts vote higher education taxes, but have a higher share of students enrolled in public schools, so the education quality, measured as spending per student decreases. In contrast, an increase in inequality in a rich district generates a decrease in the tax rate, while reducing the share of enrollment in public education which results in an increase of per student spending. Allowing for income based political power implies that even in poor districts, an increase in inequality can decrease the tax revenues, which further depresses spending per student.

Consequently, in line with the theory, in the empirical exercise below we allow the effects of inequality to vary with the income level by splitting the sample of districts by deciles of the average income per capita. Since in the model a household includes only one parent, we use household level data to construct the empirical counterparts of the model's tax base and income dispersion. Thus, in all regressions we control for the average household income and dispersion in the district. This allows us to contrast the 
comparative statics results of a change in mean income (Proposition 2 and Corollary 1 ), as well as those derived from a mean preserving spread (Proposition 3) with their empirical counterparts.

First, we estimate for each SD the mean and the standard deviation of the household income distribution using the 16 income brackets provided in the School District Tabulation data. ${ }^{8}$ The literature on inequality and public spending usually considers other measures such as the Gini coefficient or the mean/median ratio. However, given the particular hypotheses we aim to test, these measures are inadequate as they do not distinguish between changes in the mean and changes in the variance of the distribution.

We estimate the following equations:

$$
\text { Pub.Ed.Outcome } e_{i}=\alpha_{0}+\alpha_{1} \overline{\mu_{i}}+\alpha_{2} \overline{\sigma_{i}}+\alpha_{3} X_{i}+\varepsilon_{i}
$$

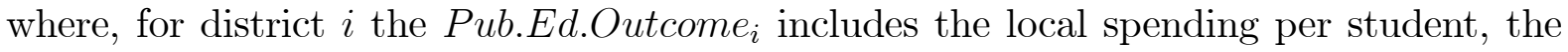
share of public enrollment and the local spending per capita ${ }^{9} \cdot \bar{\mu}_{i}$ and $\overline{\sigma_{i}}$ are estimates of the first two moments of the household income distribution and $X_{i}$ is a vector of control variables described below.

To isolate the effect of local politics on education funding, we include the state and federal revenues per student in the regression. ${ }^{10}$ State fixed effects remove further (unmodelled) idiosyncractic biases. We also control for the SD type and size using a set of eight categorical variables spanning the rural-urban axis while also accounting for size (e.g. small town, mid-size city, large city).

Other types of heterogeneity beside income have been shown to shape public spending decisions in systematic ways. Racial diversity is one of them (see Alesina et al. (1999), Boustan et al. (2010)). We therefore include a Herfindahl index of population shares as well as the share of non-white population to account for such biases. Another factor that is likely to play an important role in the political support for public education is the population age structure (see Poterba (1997), Harris et al. (2001)). Since this aspect is not explicitly addressed in the theoretical model, we add the share of residents over the age 65 to the set of controls. We also control for other characteristics that may alter the spending patterns such as education attainment and share living in poverty.

Least squares estimates are shown in table 2. For brevity, we omit all the coefficients

\footnotetext{
${ }^{8}$ All households are assigned an income equal to the mid-point of their bracket. The average income of households in the last income bracket is directly available in the data. Alternative estimates that assume, for each bracket, median income levels estimated from micro-data yield very similar results.

${ }^{9}$ In order to obtain the empirical counterpart of the model spending per capita (which is also the tax rate), we divide local public spending by the total number of households with kids. This indicator accounts both for the single parent assumption in the model as well as for the presence of households without children in the data.

${ }^{10}$ Spending controls also capture other potential biases in the state level policies, such as for example correlations induced by yardstick competition.
} 
associated with control variables. ${ }^{11}$ We report results for different subsamples, defined by the average income within district. Thus, in each table, columns 1-4 refer to cumulative subsamples ranging from the poorest $10 \%$ to the poorest $40 \%$ of the school districts. Columns 5-8 refer to the top $40 \%$ - top $10 \%$ subsamples.

Table 2: Inequality and redistribution: LS estimation results.

\begin{tabular}{lllllllll}
\hline \hline \multirow{3}{*}{ Income level } & Poorest & \multicolumn{7}{l}{ Richest } \\
& $10 \%$ & $20 \%$ & $30 \%$ & $40 \%$ & $40 \%$ & $30 \%$ & $20 \%$ & $10 \%$ \\
\hline & $(1)$ & $(2)$ & $(3)$ & $(4)$ & $(5)$ & $(6)$ & $(7)$ & $(8)$
\end{tabular}

(A) Public spending per student

\begin{tabular}{lllllllll}
\hline Mean Income & 18.51 & 21.88 & $23.64^{* *}$ & $28.59^{* * *}$ & $17.92^{* * *}$ & $15.68^{* * *}$ & $13.46^{* * *}$ & 7.26 \\
& $(0.90)$ & $(1.62)$ & $(2.16)$ & $(2.90)$ & $(5.15)$ & $(3.98)$ & $(2.97)$ & $(1.33)$ \\
Std. Dev. & -3.30 & $-5.81^{* *}$ & $-5.46^{* *}$ & $-7.87^{* * *}$ & $7.44^{* *}$ & $9.58^{* * *}$ & $12.14^{* * *}$ & $18.88^{* * *}$ \\
& $(-0.79)$ & $(-2.13)$ & $(-2.38)$ & $(-3.86)$ & $(2.42)$ & $(2.59)$ & $(2.65)$ & $(3.26)$ \\
Adj. R-Squared & 0.303 & 0.320 & 0.339 & 0.337 & 0.616 & 0.624 & 0.626 & 0.634
\end{tabular}

(B) Enrollment in public schools

\begin{tabular}{lllllllll}
\hline Mean Income & $-0.46^{* * *}-0.43^{* * *}$ & $-0.40^{* * *}-0.33^{* * *}$ & 0.01 & 0.01 & 0.02 & 0.02 \\
& $(-4.04)$ & $(-5.80)$ & $(-7.09)$ & $(-7.42)$ & $(0.46)$ & $(1.07)$ & $(1.27)$ & $(0.88)$ \\
Std. Dev. & $0.07^{* * *}$ & $0.06^{* * *}$ & $0.05^{* * *}$ & $0.04^{* * *}$ & $-0.03^{* * *}$ & $-0.04^{* * *}$ & $-0.05^{* * *}$ & $-0.07^{* * *}$ \\
& $(3.55)$ & $(4.74)$ & $(5.29)$ & $(4.77)$ & $(-3.65)$ & $(-3.54)$ & $(-3.34)$ & $(-2.98)$ \\
Adj. R-Squared & 0.199 & 0.194 & 0.176 & 0.164 & 0.263 & 0.259 & 0.261 & 0.252
\end{tabular}

(C) Public spending per capita

\begin{tabular}{|c|c|c|c|c|c|c|c|c|}
\hline Mean Income & $\begin{array}{l}18.37 \\
(0.54)\end{array}$ & $\begin{array}{l}12.17 \\
(0.58)\end{array}$ & $\begin{array}{l}7.84 \\
(0.45)\end{array}$ & $\begin{array}{l}26.13^{*} \\
(1.71)\end{array}$ & $\begin{array}{l}28.41^{\text {*** }} \\
(5.77)\end{array}$ & $\begin{array}{l}24.84^{* * *} \\
(4.58)\end{array}$ & $\begin{array}{l}26.18^{* * *} \\
(4.14)\end{array}$ & $\begin{array}{l}25.91^{\text {*** }} \\
(3.20)\end{array}$ \\
\hline Std. Dev. & $\begin{array}{l}-4.30 \\
(-0.62)\end{array}$ & $\begin{array}{l}-4.83 \\
(-1.06)\end{array}$ & $\begin{array}{l}-2.81 \\
(-0.72)\end{array}$ & $\begin{array}{l}-5.90^{*} \\
(-1.78)\end{array}$ & $\begin{array}{l}0.38 \\
(0.11)\end{array}$ & $\begin{array}{l}4.72 \\
(1.17)\end{array}$ & $\begin{array}{l}3.39 \\
(0.66)\end{array}$ & $\begin{array}{l}2.29 \\
(0.32)\end{array}$ \\
\hline Adj. R-Squared & 0.254 & 0.260 & 0.284 & 0.304 & 0.528 & 0.547 & 0.559 & 0.578 \\
\hline$\overline{\mathrm{N}}$ & 1281 & 2575 & 3865 & 5155 & 5129 & 3837 & 2559 & 1276 \\
\hline
\end{tabular}

Notes: The dependent variables are the local public spending per student, the enrollment share in public schools and the local public spending per capita, respectively. Coefficients associated with the control variables (described in the text) not reported. Public spending per student/capita is expressed in dollars. Public enrollment is expressed in percentages. The household mean income and its standard deviation are expressed in thousand dollars. For data sources and summary statistics see Appendix B. Robust standard errors within parantheses. * indicates significance at the 10 percent level, ${ }^{* *}$ indicates significance at the 5 percent level, $* * *$ indicates significance at the 1 percent level.

Part A of table 2 summarizes the effects on local public spending per student, measured in thousand dollars. Controlling for the average income, an increase in inequality

\footnotetext{
${ }^{11}$ Extended regression output is available upon request.
} 
lowers local spending per student in poor districts but increases it in rich districts, as predicted by case 3 of Proposition 3. In line with the theoretical results, the mean income has a positive effect on spending per student.

Part B of the table shows the effects on public education enrollment. Consistent with the results on spending per student, the effects of a change in inequality vary with income level. More unequal school districts rely more on public education only if the average income is low enough. In these districts, even the richest households are relatively less likely to send their children to a private school. Thus, higher inequality generates an increase in public education enrollment in poor districts but larger private enrollments in the rich ones, where more households opt out to begin with. The effects of a change in mean income is also in line with the theory: negative in the poor districts and positive in the rich ones. However, the coefficients are significant only for the poor districts.

Finally, part $\mathrm{C}$ of the table describes the effect on the overall redistribution implied by public education provision, measured by per capita spending. Inequality does not seem to produce significant effects on the fiscal burden associated with public education. The coefficients are negative for the poor districts, but only significant in the bottom $40 \%$ sample. They are positive but insignificant in the rich districts subsamples.

The effects of the tax base is positive across all subsamples but insignificant in three out of four poor district subsamples, for which the benchmark model predicts negative effects on spending. While partially corroborating the theory, data seems to suggest other mechanisms are at work as well. In section 4, we have presented evidence that political participation is not independent of income at school district level. We have then shown that including this channel in the theoretical model generated tax rates increasing in average income (albeit lower in absolute terms compared to the benchmark) and a monotonically negative response to inequality. This scenario is consistent with the observed positive tax base effects at all income levels as well as with the negative and marginally significant effect of inequality in the bottom $30 \%$ sample.

So far, the least squares estimates support the main theoretical conclusions regarding enrollment in public schools, as well as the spending per student in these schools, but yield less clear-cut evidence regarding the spending per capita. However, least squares estimates are likely biased due to reverse causality stemming from endogenous sorting across SD. To deal with this issue, we follow the approach in Boustan et al. (2010) to construct an instrumental variable that is correlated with SD inequality but is not directly linked to local education funding. This involves creating a synthetic income distribution that replaces the actual frequencies across income levels in 2000 with the corresponding 1990 shares. These are constructed by converting the endpoints of the 1990 income bins into percentiles and then projecting them onto the 2000 income scale. Integrating the 2000 district distributions within the projected bin endpoints gives the synthetic frequencies. This artificial distribution captures the residual inequality due to 
broader trends in economic activity that have shifted the aggregate income distribution and which individual SDs are too small to alter. The mean and standard deviation of this synthetic distribution are used to instrument the actual 2000 income distribution moments. Appendix $\mathrm{C}$ provides more details on the construction of the instrument. There is a strong correlation between the synthetic and the actual moments: 0.96 for the mean and 0.84 for the standard deviation.

Table 3: Inequality and redistribution: IV estimation results.

\begin{tabular}{lllllllll}
\hline \hline & Poorest & & \multicolumn{7}{c}{ Richest } \\
Income level & $10 \%$ & $20 \%$ & $30 \%$ & $40 \%$ & $40 \%$ & $30 \%$ & $20 \%$ & $10 \%$ \\
\hline & $(1)$ & $(2)$ & $(3)$ & $(4)$ & $(5)$ & $(6)$ & $(7)$ & $(8)$
\end{tabular}

(A) Public spending per student

\begin{tabular}{|c|c|c|c|c|c|c|c|c|}
\hline lean Income & $\begin{array}{l}89.34^{* *} \\
(2.04)\end{array}$ & $\begin{array}{l}99.80^{* * *} \\
(3.32)\end{array}$ & $\begin{array}{l}117.03^{* * *} \\
(4.60)\end{array}$ & $\begin{array}{l}101.52^{* * *} \\
(5.15)\end{array}$ & $\begin{array}{l}13.76^{\text {*** }} \\
(3.26)\end{array}$ & $\begin{array}{l}7.58 \\
(1.60)\end{array}$ & $\begin{array}{l}7.09 \\
(1.39)\end{array}$ & $\begin{array}{l}2.80 \\
(0.47)\end{array}$ \\
\hline d & $\begin{array}{l}-31.79^{* * *} \\
(-4.45)\end{array}$ & $\begin{array}{l}-23.25^{* * *} \\
(-4.93)\end{array}$ & $\begin{array}{l}-21.90^{* * *} \\
(-5.72)\end{array}$ & $\begin{array}{l}-23.67^{* * *} \\
(-7.37)\end{array}$ & $\begin{array}{l}12.17^{\text {*** }} \\
(2.90)\end{array}$ & $\begin{array}{l}18.68^{* * *} \\
(3.94)\end{array}$ & $\begin{array}{l}18.95^{* * *} \\
(3.62)\end{array}$ & $\begin{array}{l}21.12^{\text {*** }} \\
(3.30)\end{array}$ \\
\hline $\mathrm{dj}$. & 0.279 & 0.307 & 0.322 & 0.326 & 0.615 & 0.623 & 0.626 & 0.633 \\
\hline
\end{tabular}

(B) Enrollment in public schools

\begin{tabular}{lllllllll}
\hline Mean Income & $-0.41^{* *}$ & $-0.31^{* * *}$ & $-0.36^{* * *}$ & $-0.31^{* * *}$ & 0.02 & $0.03^{* *}$ & $0.05^{* * *}$ & $0.04^{*}$ \\
& $(-2.40)$ & $(-2.90)$ & $(-4.18)$ & $(-4.90)$ & $(1.52)$ & $(2.08)$ & $(2.58)$ & $(1.83)$ \\
Std. Dev. & 0.04 & $0.04^{* *}$ & $0.03^{*}$ & $0.03^{* *}$ & $-0.06^{* * *}$ & $-0.07^{* * *}$ & $-0.09^{* * *}$ & $-0.10^{* * *}$ \\
& $(1.60)$ & $(2.00)$ & $(1.90)$ & $(2.21)$ & $(-4.49)$ & $(-4.29)$ & $(-4.49)$ & $(-3.85)$ \\
Adj. R-Squared & 0.197 & 0.191 & 0.174 & 0.163 & 0.262 & 0.258 & 0.258 & 0.250
\end{tabular}

(C) Public spending per capita

\begin{tabular}{|c|c|c|c|c|c|c|c|c|}
\hline Mean Income & $\begin{array}{l}29.98 \\
(0.38)\end{array}$ & $\begin{array}{l}102.51^{*} \\
(1.77)\end{array}$ & $\begin{array}{l}129.74^{* * *} \\
(2.71)\end{array}$ & $\begin{array}{l}135.21^{\text {*** }} \\
(3.81)\end{array}$ & $\begin{array}{l}26.77^{* * *} \\
(4.36)\end{array}$ & $\begin{array}{l}19.30^{\text {*** }} \\
(2.81)\end{array}$ & $\begin{array}{l}23.46^{* * *} \\
(2.95)\end{array}$ & $\begin{array}{l}27.19^{* * *} \\
(2.63)\end{array}$ \\
\hline Std. Dev. & $\begin{array}{l}-39.16^{* * *} \\
(-3.47)\end{array}$ & $\begin{array}{l}-28.84^{* * *} \\
(-3.61)\end{array}$ & $\begin{array}{l}-25.61^{* * *} \\
(-3.99)\end{array}$ & $\begin{array}{l}-26.19^{* * *} \\
(-4.93)\end{array}$ & $\begin{array}{l}4.53 \\
(0.87)\end{array}$ & $\begin{array}{l}12.53^{* *} \\
(2.09)\end{array}$ & $\begin{array}{l}7.84 \\
(1.10)\end{array}$ & $\begin{array}{l}1.29 \\
(0.13)\end{array}$ \\
\hline Adj. R-Squared & 0.230 & 0.250 & 0.269 & 0.292 & 0.528 & 0.546 & 0.559 & 0.578 \\
\hline$\overline{\mathrm{N}}$ & 1281 & 2575 & 3865 & 5155 & 5129 & 3837 & 2559 & 1276 \\
\hline
\end{tabular}

Notes: The dependent variables are the local public spending per student, the enrollment share in public schools and the local public spending per capita, respectively. Coefficients associated with the control variables (described in the text) not reported. Public spending per student/capita is expressed in dollars. Public enrollment is expressed in percentages. The school district mean household income and its standard deviation are expressed in thousand dollars. For data sources and summary statistics see Appendix B. Robust standard errors within parantheses. $*$ indicates significance at the 10 percent level, $* *$ indicates significance at the 5 percent level, ${ }^{* * *}$ indicates significance at the 1 percent level.

Table 3 shows the instrumental variable estimates. Relative to the least squares esti- 
mates, the coefficients of inequality increase in absolute value, while remaining strongly significant in all subsamples. Computing the LM test of the Kleibergen-Paap rk statistic, we reject the weak instrument hypothesis at any customary confidence level. ${ }^{12}$ As before, local spending per student (see part A) in districts at the top of the income distribution varies positively with inequality while the opposite pattern occurs in the poor districts. The average income has a positive and significant effect on public spending per student in all but top $30 \%$ districts, in line with results in Corollary 1. In part B of the table, showing effects on public school enrollment, the coefficients of the income standard deviation are negative and strongly significant in rich districts while positive and significant in all poor districts but the bottom $10 \%$.

Regarding spending per capita, the estimates in part $\mathrm{C}$ of the table maintain the sign of the least squares coefficients and become strongly significant in poor districts, showing that redistribution decreases with income dispersion at the bottom of the distribution while it does not change significantly with inequality in the rich districts. For poor districts, this last finding is consistent with the political power model where rich households exert a disproportionate influence on the public spending for education. In these districts, higher dispersion in income leads to higher enrollments in public schools despite reduced funding at local level.

While, from a strictly statistical point of view, the largely insignificant link between education funding and inequality in rich districts can be taken to provide weak evidence supporting the results on the tax revenues, the positive signs suggest that other factors such as tax progressivity or different preferences for education - might affect the behavior of the local tax revenues. Recall, for example, that case 2 of Proposition 2 established that for high values of $\gamma$, the tax rate increases with inequality. If rich districts are characterized by higher altruism toward children, beyond that captured in parental characteristics included in the regression, this would induce a systematic positive response of tax rates to inequality in these districts.

To sum up, our empirical exercises using school district data from the United States provide strong support for opposite effects of a change in inequality at different income levels.

\subsection{Robustness}

Besides the controls described in the previous sections, we performed a number of additional robustness tests. We used deciles of the average household income and median family income to split the sample, rather than average income per capita. As an

\footnotetext{
${ }^{12}$ We compute the test using ivreg2 command in Stata 10 and obtain values above 180 . The test statistic is distributed $\chi^{2}$ with $L_{1}-k_{1}+1$ degrees of freedom where $L_{1}$ is the number of excluded instruments and $k_{1}$ the number of endogenous regressors. For more details, see Kleibergen and Paap (2006).
} 
alternative measure of public education quality, we considered instructional spending per student instead of total local spending per student. We expanded the set of geographical control variables to include a measure of remoteness (fringe/distant/remote), in addition to urbanization degree and size as well as an alternative set of indicators capturing the position of the SD relative to the closest metropolitan area. As strategic behavior of the SDs, such as fiscal competition, could potentially alter our results, we have also controlled for the spending per student/capita in the SD closest in space, in terms of linear distance. In order to test the robustness of the coefficients' signs to possible multicollinearity issues, we have also run all the regressions alternatively excluding correlated variables, such as the share of college graduates, average household income or the share of residents over the age 65. A number of communities are served by overlapping SDs, dealing separately with elementary and secondary education. To avoid any double counting biases, we also estimated our equations excluding "secondary only" school districts. The main empirical results survive all these exercises.

We also computed clustered standard errors at state level in order to address any systematic bias in the response of the dependent variables beyond that captured by the set of fixed effects. As an alternative estimation strategy, we created an indicator for school districts below the median income per capita and estimated similar regressions using the entire sample and interacting the mean and the standard deviation variables with this indicator. In a different approach, we introduced a linear and a quadratic term for the mean income in addition to the interaction with the dispersion. These regressions, which practically restrict all other slopes and intercepts to be identical across income groups, provided similar results and were excluded due to space considerations. ${ }^{13}$

\section{Conclusion}

The paper investigates the role of inequality in the determination of public education spending, using a probabilistic voting model of public education provision with a private schooling option and endogenous fertility. We show that modelling household income heterogeneity to be consistent with the skewness of empirical income distributions has important consequences for the qualitative properties of the political equilibrium.

Generalizing results in the previous literature, we find a non-monotonic relationship between inequality and per student public spending, depending on 1) the preference for fertility relative to children quality and 2) the average per capita income (the tax base) in the economy. For moderate fertility preferences, we show that a mean preserving spread decreases public spending per student but increases tax rates and public school enrollments when the average income per capita is low, while it has opposite effects in

\footnotetext{
${ }^{13}$ They are available upon request from the authors.
} 
richer economies. A marginal increase in the tax base, holding income dispersion constant, also yields non-monotonic effects.

In the benchmark framework the households enjoy equal influence in local education politics. We show that in the U.S., participation in local education politics varies with socioeconomic indicators. We then extend the basic model to include income dependent political power and study its properties.

Finally, the empirical analysis of U.S. school district data lends strong support to predictions derived from the theoretical model.

While the paper focuses on the effects of inequality on education spending, investigating the dynamic effects of education in this setup, endogenizing sorting across districts and exploring policy implications are all interesting topics for future research.

\section{References}

Alesina, A., R. Baqir, and W. Easterly (1999). Public Goods And Ethnic Divisions. The Quarterly Journal of Economics 114(4), 1243-1284.

Alesina, A., E. Glaeser, and B. Sacerdote (2001). Why Doesn't the US Have a EuropeanStyle Welfare System? Brookings Papers on Economic Activity (2), 187-277.

Bénabou, R. (1997). Inequality and Growth. NBER Working Papers.

Bénabou, R. (2000). Unequal Societies: Income Distribution and the Social Contract. American Economic Review 90(1), 96-129.

Boustan, L., F. Ferreira, H. Winkler, and E. M. Zolt (2010). Inequality and Local Government: Evidence from U.S. Cities and School Districts, 1970-2000. Law and Economics Workshop, Berkeley Program in Law and Economics, UC Berkeley.

Corcoran, S. and W. N. Evans (2009). Income Inequality, the Median Voter, and the Support for Public Education. Department of Economics, University of Notre Dame.

de la Croix, D. and M. Doepke (2009). To Segregate or to Integrate: Education Politics and Democracy. Review of Economic Studies 76(2), 597-628.

Fernandez, R. and G. Levy (2008). Diversity and redistribution. Journal of Public Economics 92(5-6), 925-943.

Gans, J. S. and M. Smart (1996). Majority voting with single-crossing preferences. Journal of Public Economics 59(2), 219-237.

Glomm, G. (2004). Inequality, Majority Voting And The Redistributive Effects Of Public Education Funding. Pacific Economic Review 9(2), 93-101.

Goldin, C. and L. F. Katz (1997). Why the United States Led in Education: Lessons from Secondary School Expansion, 1910 to 1940. NBER Working Papers.

Gradstein, M., M. Justman, and V. Meier (2005). The Political Economy of Education: Implications for Growth and Inequality. CESifo Book Series. MIT. 
Hajnal, Z. L. and P. G. Lewis (2003). Municipal Institutions and Voter Turnout in Local Elections. Urban Affairs Review 38(5), 645-668.

Harris, A. R., W. N. Evans, and R. M. Schwab (2001). Education Spending in an Aging America. Journal of Public Economics 81, 449-472.

Kleibergen, F. and R. Paap (2006). Generalized reduced rank tests using the singular value decomposition. Journal of Econometrics 133(1), 97-126.

Lee, W. and J. E. Roemer (1998). Income Distribution, Redistributive Politics, and Economic Growth. Journal of Economic Growth 3(3), 217-240.

Lind, J. T. (2007). Fractionalization and the size of government. Journal of Public Economics 91(1-2), 51-76.

Lindert, P. H. (1996). What Limits Social Spending? Explorations in Economic History 33(1), 1-34.

Luttmer, E. F. P. (2001). Group Loyalty and the Taste for Redistribution. Journal of Political Economy 109(3), 500-528.

Meltzer, A. H. and S. F. Richard (1981). A Rational Theory of the Size of Government. The Journal of Political Economy 89(5), 914-927.

Morlan, R. L. (1984). Municipal versus national election voter turnout: Europe and the United States. Political Science Quarterly 99, 457-470.

Nechyba, T. J. (1999). School Finance Induced Migration and Stratification Patterns: The Impact of Private School Vouchers. Journal of Public Economic Theory 1(1), $5-50$.

Perotti, R. (1996). Growth, Income Distribution, and Democracy: What the Data Say. Journal of Economic Growth 1(2), 149-87.

Persson, T. and G. Tabellini (1994). Is Inequality Harmful for Growth? American Economic Review 84(3), 600-621.

Persson, T. and G. Tabellini (2002). Political Economics: Explaining Economic Policy. MIT Press Books. The MIT Press.

Poterba, J. M. (1997). Demographic Structure and the Political Economy of Public Education. Journal of Policy Analysis and Management 16, 48-66.

Rosenstone, S. J. and J. M. Hansen (1993). Mobilization, Participation, and Democracy in America. New York: Macmillan Publishing Company.

Soares, J. (1998). Altruism and Self-interest in a Political Economy of Public Education. IGIER working paper, Bocconi University.

Verba, S., S. K. Lehman, and H. E. Brady (1995). Voice and Equality: Civic Voluntarism in American Politics. Cambridge, Mass.: Harvard University Press. 


\section{Appendix A}

Proof of Proposition 1. The LHS of equation (18) is continuous and increasing in $\widetilde{y}$, while the $R H S$ is continuous and decreasing in $\widetilde{y}$. Moreover, $\lim _{\widetilde{y} \rightarrow \infty} L H S(\widetilde{y})=\infty>$ $\lim _{\widetilde{y} \rightarrow \infty} \operatorname{RHS}(\widetilde{y})=\mu /[\delta(1+\gamma \theta)]$. Next, $R H S\left(y_{l}\right)=\mu / \delta=\alpha y_{l} /[\delta(\alpha-1)]>\operatorname{LHS}\left(y_{l}\right)=y_{l}$. By Intermediate Value Theorem, the solution of equation (18) is interior and unique.

Proof of Proposition 2. First we compute $\partial f(\mu, \sigma) / \partial \mu$ :

$$
\begin{aligned}
\frac{\partial f(\mu, \sigma)}{\partial \mu} & =f(\mu, \sigma)\left[\frac{\partial \alpha}{\partial \mu} \log \left(\frac{y_{l}}{\widetilde{y}^{*}}\right)+\alpha \frac{\widetilde{y}^{*} \frac{\partial y_{l}}{\partial \mu} \widetilde{y}^{*}-y_{l} \frac{\partial \widetilde{y}^{*}}{\partial \mu}}{\left(\widetilde{y}^{*}\right)^{2}}\right] \\
& =f\left[\frac{\partial \alpha}{\partial \mu} \log \left(\frac{y_{l}}{\widetilde{y}^{*}}\right)+\frac{\alpha}{y_{l}} \frac{\partial y_{l}}{\partial \mu}\right]-f \frac{\alpha}{\widetilde{y}^{*}} \frac{\partial \widetilde{y}^{*}}{\partial \mu}
\end{aligned}
$$

We use (1) to get solve $y_{l}$ and $\alpha$ as functions of the first two moments, $\mu$ and $\sigma$ :

$$
y_{l}(\mu, \sigma)=\frac{\alpha(\mu, \sigma)-1}{\alpha(\mu, \sigma)} \mu, \text { and } \alpha(\mu, \sigma)=1+\sqrt{1+\frac{\mu^{2}}{\sigma^{2}}} .
$$

We use (A.3) to find $\partial y_{l} / \partial \mu$ :

$$
\frac{\partial y_{l}}{\partial \mu}=\frac{\alpha-1}{\alpha}+\frac{\mu}{\alpha^{2}} \frac{\partial \alpha}{\partial \mu}
$$

where

$$
\frac{\partial \alpha}{\partial \mu}=\left(1+\frac{\mu^{2}}{\sigma^{2}}\right)^{-1 / 2} \frac{\mu}{\sigma^{2}}>0
$$

Using (A.4) and

$$
\frac{\alpha}{\widetilde{y}^{*}} \frac{\partial \widetilde{y}^{*}}{\partial \mu}=\frac{\partial q^{*}}{\partial \mu} \frac{\alpha}{q^{*}}
$$

in (A.2), we obtain:

$$
\frac{\partial f(\mu, \sigma)}{\partial \mu}=f\left[\frac{\partial \alpha}{\partial \mu} \log \left(\frac{y_{l}}{\widetilde{y}^{*}}\right)+\frac{\alpha-1}{y_{l}}+\frac{\mu}{\alpha y_{l}} \frac{\partial \alpha}{\partial \mu}\right]-f \frac{\alpha}{q^{*}} \frac{\partial q^{*}}{\partial \mu}
$$

Next, we use (19) to rewrite $\partial q^{*} / \partial \mu$ in (23):

$$
\begin{gathered}
1+\gamma \theta(1-f)=\frac{\phi \theta \mu}{q^{*}} \\
\frac{\partial q^{*}}{\partial \mu}=\frac{\left(q^{*}\right)^{2}}{\phi \mu}\left\{\frac{\phi}{q^{*}}+\gamma \frac{\partial f(\mu, \sigma)}{\partial \mu}\right\} .
\end{gathered}
$$


We use (A.7) in (A.9) and $y_{l}=(\alpha-1) \mu / \alpha$. Rearranging terms, we get:

$$
\frac{\partial q^{*}}{\partial \mu}\left(1+f \frac{\alpha \gamma}{\phi} \frac{q^{*}}{\mu}\right)=\frac{q^{*}}{\mu}+\frac{\alpha \gamma}{\phi} \frac{\left(q^{*}\right)^{2}}{\mu^{2}} f+\frac{\left(q^{*}\right)^{2}}{\phi \mu} \gamma f \frac{\partial \alpha}{\partial \mu} \underbrace{\left[\log \left(\frac{y_{l}}{\widetilde{y}^{*}}\right)+\frac{\mu}{\alpha y_{l}}\right]}_{\omega(\mu, \sigma)} .
$$

From equation (22) we see that $\operatorname{sign}\left(\partial N^{*} / \partial \mu\right)=\operatorname{sign}\left(q^{*}-\mu\left(\partial q^{*} / \partial \mu\right)\right)$. We use (A.10) and $y_{l}=(\alpha-1) \mu / \alpha$ to compute $q^{*}-\mu\left(\partial q^{*} / \partial \mu\right)$. We obtain:

$$
q^{*}-\mu \frac{\partial q^{*}}{\partial \mu}=-\frac{\gamma f \frac{\left(q^{*}\right)^{2}}{\phi \mu} \frac{\partial \alpha}{\partial \mu}\left[\log \left(\frac{y_{l}}{\widetilde{y}^{*}}\right)+\frac{\mu}{\alpha y_{l}}\right]}{1+f \frac{\alpha \gamma}{\phi} \frac{q^{*}}{\mu}}
$$

Denote by $\omega(\mu, \sigma)=\log \left(y_{l} / \widetilde{y}^{*}\right)+\mu /\left(\alpha y_{l}\right)$. As $\partial \alpha / \partial \mu>0, \operatorname{sign}\left(q^{*}-\mu\left(\partial q^{*} / \partial \mu\right)\right)=$ $-\operatorname{sign}(\omega(\mu, \sigma)) \Longrightarrow \operatorname{sign}\left(\partial N^{*} / \partial \mu\right)=-\operatorname{sign}(\omega(\mu, \sigma))$.

Next, we study the $\operatorname{sign}(\omega(\mu, \sigma))$. From the expression of $\omega(\mu, \sigma)$ we see that $\omega(\mu, \sigma) \geqslant$ $0 \Longleftrightarrow \mu /\left(\alpha y_{l}\right) \geqslant \log \left(\widetilde{y}^{*} / y_{l}\right) \Longleftrightarrow \widetilde{y}^{*} \leqslant \widehat{y}$, where $\widehat{y}=y_{l} e^{\mu /\left(\alpha y_{l}\right)}$.

Using the expressions for $y_{l}$ and $\alpha$ from (A.3), we can express $\widehat{y}$ as a function of the first two moments of the income distribution, $\mu$ and $\sigma$ :

$$
\widehat{y}(\mu, \sigma)=\mu \frac{z}{z+1} e^{1 / z}
$$

where $z=\sqrt{1+\mu^{2} / \sigma^{2}}$ and $e$ is the Euler number.

In order to see if $\widetilde{y}^{*} \leqslant \widehat{y}$ holds, we evaluate the $L H S$ and $R H S$ of equation (18) at $\widehat{y}$. The $L H S$ is increasing in $\widetilde{y}$, while the $R H S$ is decreasing in $\widetilde{y}$. Thus, the inequality $\widetilde{y}^{*} \leqslant \widehat{y}$ holds if $\operatorname{LHS}(\widehat{y}(\mu, \sigma)) \geqslant R H S(\widehat{y}(\mu, \sigma))$, or

$$
\underbrace{\delta \frac{z}{z+1} e^{1 / z}}_{h(\mu)} \geqslant \underbrace{\frac{1}{1+\gamma \theta\left[1-e^{-(1+z) / z}\right]}}_{v(\mu)} .
$$

Notice that the inequality implies a restriction in $\mu$ and $\sigma$. In the following, we study the properties of functions $h(\mu, \sigma)$ and $v(\mu, \sigma)$.

$$
\begin{aligned}
\frac{\partial h}{\partial \mu} & =\left(1+\frac{\mu^{2}}{\sigma^{2}}\right)^{-1 / 2} \frac{\mu}{\sigma^{2}}\left[\delta \frac{e^{1 / z}}{(z+1)^{2}}-\delta \frac{z e^{1 / z}}{z+1} z^{-2}\right] \\
& =-\left(1+\frac{\mu^{2}}{\sigma^{2}}\right)^{-1 / 2} \frac{\mu}{\sigma^{2}} \frac{\delta e^{1 / z}}{z(z+1)^{2}}<0 \\
\frac{\partial v}{\partial \mu} & =\frac{e^{-(1+z) / z}}{\left\{1+\gamma \theta\left[1-e^{-(1+z) / z}\right]\right\}^{2}} \frac{1}{z^{2}}\left(1+\frac{\mu^{2}}{\sigma^{2}}\right)^{-1 / 2} \frac{\mu}{\sigma^{2}}>0
\end{aligned}
$$

Consequently, $h(\mu)$ is decreasing and $v(\mu)$ is increasing in $\mu \in(0, \infty)$. Both functions are continuous. In addition, $\lim _{\mu \rightarrow 0} h(\mu)=\delta e / 2, \lim _{\mu \rightarrow 0} v(\mu)=1 /\left[1+\gamma \theta\left(1-e^{-2}\right)\right], \lim _{\mu \rightarrow \infty} h(\mu)=\delta$, 
and $\lim _{\mu \rightarrow \infty} v(\mu)=1 /\{1+\gamma \theta[1-(1 / e)]\}$.

We distinguish three cases:

1) $\lim _{\mu \rightarrow 0} v(\mu) \geqslant \lim _{\mu \rightarrow 0} h(\mu) \Longleftrightarrow 1 /\left[1+\gamma \theta\left(1-e^{-2}\right)\right] \geqslant \delta \exp / 2 \Longleftrightarrow \gamma \leqslant \underline{\gamma}=[(2 /(\delta e)-1] /[\theta(1-$ $\left.e^{-2}\right] ;$ In this case $h(\mu)<v(\mu)$ for any $\mu \in(0, \infty) \Longrightarrow \widetilde{y}^{*}>\widehat{y} \Longrightarrow \omega(\mu)<0 \Longrightarrow \partial N^{*} / \partial \mu>$ 0 ;

2) $\lim _{\mu \rightarrow \infty} v(\mu) \leqslant \lim _{\mu \rightarrow \infty} h(\mu) \Longleftrightarrow \gamma \geqslant \bar{\gamma}=[(1 / \delta)-1] /\{\theta[1-(1 / e)]\} ;$ In this case $h(\mu)>$ $v(\mu)$ for any $\mu \in(0, \infty) \Longrightarrow \widetilde{y}^{*}<\widehat{y} \Longrightarrow \omega(\mu)>0 \Longrightarrow \partial N^{*} / \partial \mu<0$;

3) $\left\{\begin{array}{c}\lim _{\mu \rightarrow 0} v(\mu)<\lim _{\mu \rightarrow 0} h(\mu) \\ \lim _{\mu \rightarrow \infty} v(\mu)>\lim _{\mu \rightarrow \infty} h(\mu)\end{array} \Longleftrightarrow\left\{\begin{array}{l}\gamma>\underline{\gamma}=[(2 /(\delta e))-1] /\left[\theta\left(1-e^{-2}\right)\right] \\ \gamma<\bar{\gamma}=[(1 / \delta)-1] /\{\theta[1-(1 / e)]\}\end{array}\right.\right.$

In this case, by the Intermediate Value Theorem, the two function intersect once in $\widehat{\mu} \in(0, \infty)$. There are two subcases here:

3.1) $\mu \in(0, \widehat{\mu}] \Longrightarrow h(\mu) \geqslant v(\mu) \Longrightarrow \widetilde{y}^{*} \leqslant \widehat{y} \Longrightarrow \omega(\mu) \geqslant 0 \Longrightarrow \partial N^{*} / \partial \mu \leqslant 0$;

3.2) $\mu \in(\widehat{\mu}, \infty) \Longrightarrow h(\mu)<v(\mu) \Longrightarrow \widetilde{y}^{*}>\widehat{y} \Longrightarrow \omega(\mu)<0 \Longrightarrow \partial N^{*} / \partial \mu>0$.

Proof of Corollary 1. We use equation (A.10). As $\partial \alpha / \partial \mu>0$, if $\omega(\mu, \sigma)>0$ then $\partial q^{*} / \partial \mu>0$. As established in Proposition 2, $\omega(\mu, \sigma)>0$ when $\gamma \geqslant \bar{\gamma}$ or when $\gamma \in(\underline{\gamma}, \bar{\gamma})$ and $\mu \in(0, \widehat{\mu})$.

Consider the case when $\gamma \in(\gamma, \bar{\gamma})$. As the $R H S$ of equation (A.10) contains some other positive terms in addition to $\omega(\mu, \sigma) \Longrightarrow$ there exists $\widetilde{\mu}>\widehat{\mu}$ such that $\partial q^{*} / \partial \mu>0$ on the interval $\mu \in(0, \widetilde{\mu})$.

Proof of Proposition 3. First, we take the derivative of $f(\sigma)$ with respect to $\sigma$ :

$$
\begin{aligned}
\frac{\partial f(\sigma)}{\partial \sigma} & =f(\sigma)\left[\frac{\partial \alpha}{\partial \sigma} \log \left(\frac{y_{l}}{\widetilde{y}^{*}}\right)+\alpha \frac{\widetilde{y}^{*}}{y_{l}} \frac{\frac{\partial y_{l}}{\partial \sigma} \widetilde{y}^{*}-y_{l} \frac{\partial \widetilde{y}^{*}}{\partial \sigma}}{\left(\widetilde{y}^{*}\right)^{2}}\right] \\
& =f(\sigma)\left[\frac{\partial \alpha}{\partial \sigma} \log \left(\frac{y_{l}}{\widetilde{y}^{*}}\right)+\frac{\alpha}{y_{l}} \frac{\partial y_{l}}{\partial \sigma}\right]-f(\sigma) \frac{\alpha}{\widetilde{y}^{*}} \frac{\partial \widetilde{y}^{*}}{\partial \sigma}
\end{aligned}
$$

Next, we calculate $\partial \widetilde{y}^{*} / \partial \sigma=\left(\partial q^{*} / \partial \sigma\right) / \phi \theta \delta, \partial \alpha / \partial \sigma=-\left(\mu^{2} / \sigma^{3}\right)\left[1+(\mu / \sigma)^{2}\right]^{-1 / 2}<0$, $\partial y_{l} / \partial \sigma=\left(\mu / \alpha^{2}\right)(\partial \alpha / \partial \sigma)<0$. We use (A.17) in the expression of $\left(\partial q^{*} / \partial \sigma\right),(24)$ and group terms to obtain:

$$
\frac{\partial q^{*}}{\partial \sigma} \underbrace{\left\{1+\frac{\mu f(\sigma)}{1+\gamma \theta[1-f(\sigma)]^{2}} \frac{\alpha}{\delta} \frac{1}{\widetilde{y}^{*}}\right\}}_{+}=\underbrace{\frac{\phi \theta \mu f(\sigma)}{1+\gamma \theta[1-f(\sigma)]^{2}}}_{+} \underbrace{\frac{\partial \alpha}{\partial \sigma}}_{-} \underbrace{\left[\log \left(\frac{y_{l}}{\widetilde{y}^{*}}\right)+\frac{\mu}{\alpha y_{l}}\right]}_{\omega(\mu, \sigma)} .
$$

From the expression above we can see that $\operatorname{sign}\left(\partial q^{*} / \partial \sigma\right)=-\operatorname{sign}(\omega(\mu, \sigma))$. Also, $\operatorname{sign}\left(\partial N^{*} / \partial \sigma\right)=\operatorname{sign}\left(\partial \tau^{*} / \partial \sigma\right)=\operatorname{sign}(\omega(\mu, \sigma))$.

We studied the properties of the function $\omega(\mu, \sigma)$ in the proof of Proposition 2. Thus, there are three cases:

1) $\gamma \leqslant \underline{\gamma}=\left[(2 /(\delta e)-1] /\left[\theta\left(1-e^{-2}\right] \Longrightarrow \omega(\mu)<0 \Longrightarrow \partial \tau^{*} / \partial \sigma<0, \partial N^{*} / \partial \sigma<\right.\right.$ $0, \partial q^{*} / \partial \sigma>0$ 
2) $\gamma \geqslant \bar{\gamma}=[(1 / \delta)-1] /\{\theta[1-(1 / e)]\} \Longrightarrow \omega(\mu)>0 \Longrightarrow \partial \tau^{*} / \partial \sigma>0, \partial N^{*} / \partial \sigma>$ $0, \partial q^{*} / \partial \sigma<0$

3) $\gamma \in(\underline{\gamma}, \bar{\gamma})$. There are two subcases here:

3.1) $\mu \in(0, \widehat{\mu}] \Longrightarrow \omega(\mu) \geqslant 0 \Longrightarrow \partial \tau^{*} / \partial \sigma \geqslant 0, \partial N^{*} / \partial \sigma \geqslant 0, \partial q^{*} / \partial \sigma \leqslant 0$;

3.2) $\mu \in(\widehat{\mu}, \infty) \Longrightarrow \omega(\mu)<0 \Longrightarrow \partial \tau^{*} / \partial \sigma<0, \partial N^{*} / \partial \sigma<0, \partial q^{*} / \partial \sigma>0$.

Proof of Proposition 4. The equilibrium enrollment is determined by

$$
\widetilde{y}=\frac{\mu}{\delta} \frac{1}{1-\left(\frac{y_{l}}{\widetilde{y}}\right)^{\alpha}} \frac{1-\left(\frac{y_{l}}{\widetilde{y}}\right)^{\alpha-\nu}}{1+\gamma \theta\left(1-\left(\frac{y_{l}}{\widetilde{y}}\right)^{\alpha-\nu}\right)}
$$

As $y_{l} / \widetilde{y}<1$ and $\alpha>2,\left(y_{l} / \widetilde{y}\right)^{\alpha} \ll 1$. Since $\ln (1+x) \simeq x$, for $x \ll 1$,

$$
\begin{aligned}
\ln \left(1-\left(y_{l} / \widetilde{y}\right)^{\alpha}\right) & \simeq\left(y_{l} / \widetilde{y}\right)^{\alpha} \\
\ln \left(1+\gamma \theta\left(1-\left(y_{l} / \widetilde{y}\right)^{\alpha-\nu}\right)\right. & \simeq \ln (1+\gamma \theta)-\frac{\gamma \theta}{1+\gamma \theta}\left(y_{l} / \widetilde{y}\right)^{\alpha-\nu} .
\end{aligned}
$$

Thus, (A.19) can be approximated by

$$
\ln y_{l}-\ln z=\ln \frac{\mu}{\delta(1+\gamma \theta)}+z^{\alpha}-\frac{1}{1+\gamma \theta} z^{\alpha-\nu}
$$

where $z=\left(y_{l} / \widetilde{y}\right) \in(0,1]$. Denote the left and the right hand sides of (A.20) with LHS and RHS respectively. It is easy to verify that $\lim _{z \rightarrow 0} L H S=+\infty$ and $\lim _{z \rightarrow 1} L H S=\ln y_{l}$, $\lim _{z \rightarrow 0} R H S=\ln (\mu /(\delta(1+\gamma \theta)))$ and $\lim _{z \rightarrow 1} R H S=\ln (\underset{z \rightarrow 0}{(\mu /(\delta(1+\gamma \theta))})+\gamma \theta /(1+\gamma \theta)$. LHS is monotonically decreasing in $z$, while the RHS can be first decreasing and then increasing in $z$. (i) Thus a sufficient condition for uniqueness is

$$
\ln (\mu /(\delta(1+\gamma \theta)))<\ln y_{l}
$$

If furthermore $\ln (\mu /(\delta(1+\gamma \theta)))+\gamma \theta /(1+\gamma \theta)>\ln y_{l}$, the equilibrium enrollment is interior, otherwise $z=1=>\widetilde{y}^{*}=y_{l}$. Using the definition of $\delta$ and (A.3) in (A.21) and solving for $\gamma$ results in $\gamma>\left(e^{k}-1\right) / \theta$, where $k=-(\ln (1 / 2)+\ln \delta)>0$. Thus, if household's concern for children is high enough, there is a unique equilibrium threshold for private enrollment.

(ii) This sufficient condition that does not depend on $\nu$, the political power parameter. Intuitively, as $\nu$ goes to zero, the problem is reduced to the benchmark, which has a unique equilibrium. However, a more general sufficient condition on $\nu$ can be found. Since $\partial L H S / \partial z<0$, imposing $\partial R H S / \partial z>0$ guarantees uniqueness. This condition can 
be further rewritten as

$$
z^{\nu} \alpha(1+\gamma \theta)+\alpha-\nu<0 \Leftrightarrow \nu<\frac{\ln (1+\gamma \theta)}{-\ln z} .
$$

Thus, for any $z<1$, one can always find a small enough $\nu$ to ensure uniqueness.

\section{Appendix B}

Table 4: Summary statistics

\begin{tabular}{lcccc}
\hline \hline \multicolumn{1}{c}{ Variable } & Mean & Std. Dev. & Min. & Max. \\
\hline Average income per capita & 19625.62 & 7639.96 & 4016 & 105002 \\
Average household income & 51594.53 & 21356.33 & 13937.14 & 295694.5 \\
Public ed. enrollment share & 3499.15 & 15173.53 & 8 & 1075710 \\
Public ed. spending per student & 3696.03 & 2523.09 & 288.83 & 17900.45 \\
Public ed. spending per capita & 4185.78 & 2781.95 & 100 & 40028.57 \\
Share of public ed. enrollment & 91.13 & 6.81 & 32.41 & 100 \\
Local revenues per student & 3696.03 & 2523.09 & 289 & 17900 \\
State revenues per student & 4122.57 & 2121.8 & 73 & 108600 \\
Federal revenues per student & 504.52 & 688.85 & 0 & 30897 \\
Racial diversity index & 0.82 & 0.17 & 0.22 & 1 \\
Share 65+ & 19 & 5.83 & 0 & 71.96 \\
Share with college & 46.1 & 13.98 & 5.95 & 96.03 \\
Share in poverty & 11.65 & 7.39 & 0.08 & 81.43 \\
Share non-white & 12.85 & 16.34 & 0 & 99.01 \\
\hline \multicolumn{5}{c}{$\mathrm{N}$} \\
\hline \hline
\end{tabular}

The school district characteristics, including all funding variables, are taken from the Common Core of Data (CCD) survey maintained by NCES. The data on public and private enrollment is taken from the Census 2000 School District Tabulation (STP2), using the Children ( $\mathrm{CO}$ ) tabulation universe. Here a child is defined as a person age 0 to 17 (as of April 1, 2000) or a person age 18 or 19 who is not a high school graduate (based on the educational attainment response from the Census 2000 questionnaire). Household income data and racial composition is available from the same source, using the Total (population and households) (TT) universe. 16 income brackets are available for 2000 and 25 for 1990. The full sample contains 12865 observations. School districts are deemed outliers if per-student local revenues are more than twice the 95th percentile, or less than $1 / 4$ of the 5 th percentile nationwide. School districts of Alaska, Hawaii, and the District of Columbia are excluded. 


\section{Appendix C}

The following steps outline the construction of the synthetic inequality instrument:

1. For each of the 25 bins that describe the income distribution at school district (SD) level, transform their endpoints into percentiles of the aggregate 1990 household income distribution;

2. Obtain the dollar equivalents of each such percentiles on the aggregate 2000 household income distribution; the synthetic cutoffs effectively translate the 1990 density onto the 2000 income axis;

3. Use the synthetic cutoffs to construct synthetic income brackets in 2000; for each $\mathrm{SD}$, attribute population mass from the actual 1990 income brackets to the corresponding synthetic intervals on the 2000 income axis; the resulting distribution has 25 bins;

4. For each SD, using the 16 income brackets that describe the SD actual income distribution in 2000, integrate over the relevant probability mass to obtain the synthetic 2000 income distribution with 16 bins; while having identical cutoffs as the actual 2000 distributions, the density of the synthetic distributions reflects exclusively how the 1990 $\mathrm{SD}$ income distributions responded to national trends in income inequality;

5. Using the synthetic frequencies at SD level, estimate the mean and the standard deviation of each income distribution.

The aggregate household income distributions in 1990 and 2000 are estimated based on the respective $1 \%$ Census samples.

\section{Appendix D}

The figures below describe the model's comparative statics with and without political power under extreme fertility preferences. 
Figure 5: Low preference for fertility: $\gamma \leqslant \underline{\gamma}$
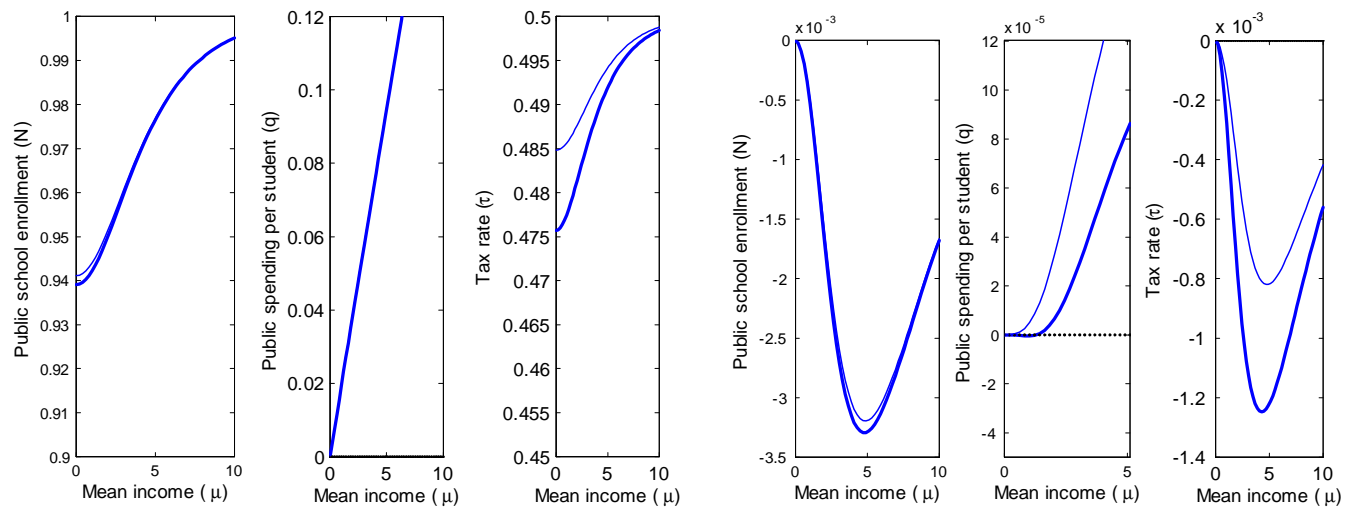

(a) Tax base effects

(b) Mean Preserving Spread

Main education variables as a function of the mean income, keeping dispersion constant (panel a) and Changes in main variables in response to a 10 percent increase in dispersion, at each level of mean income (panel b) under political power $(\nu=0.3$, thick line) versus benchmark $(\nu=0$, thin line). $\theta=0.5, \gamma=2$.

Figure 6: High preference for fertility: $\gamma \geqslant \bar{\gamma}$
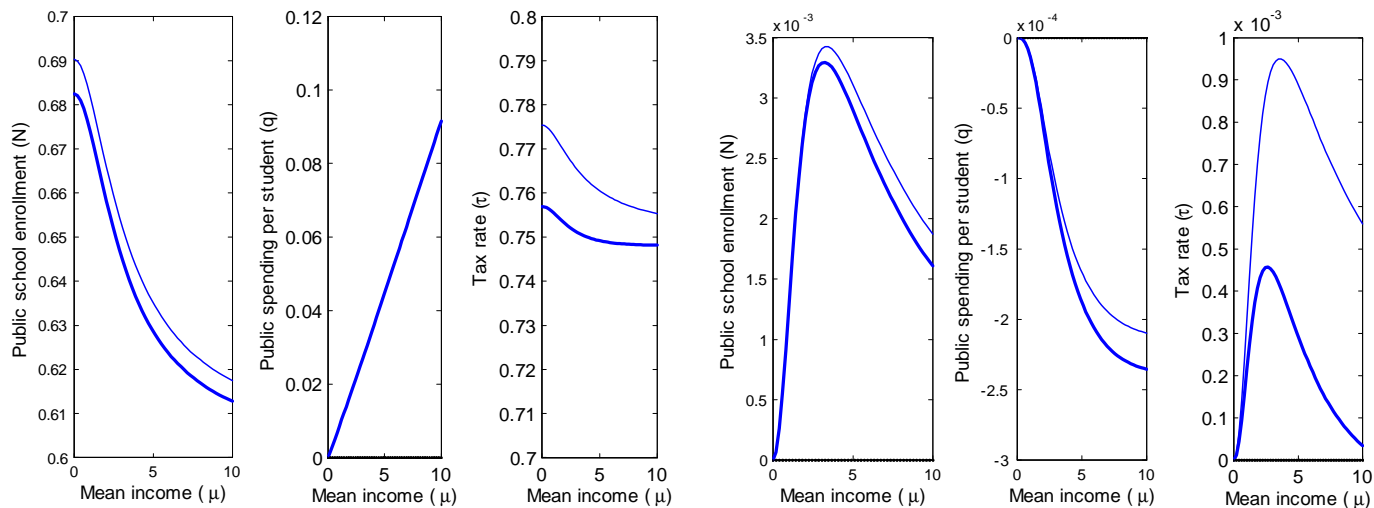

(a) Tax base effects

(b) Mean Preserving Spread

Main education variables as a function of the mean income, keeping dispersion constant (panel a) and Changes in main variables in response to a 10 percent increase in dispersion, at each level of mean income (panel b) under political power $(\nu=0.3$, thick line) versus benchmark $(\nu=0$, thin line). $\theta=0.5, \gamma=10$. 